NBER WORKING PAPER SERIES

\title{
THE EFFECTS OF PHARMACEUTICAL MARKETING AND PROMOTION ON ADVERSE DRUG EVENTS AND REGULATION
}

\author{
Guy David \\ Sara Markowitz \\ Seth Richards \\ Working Paper 14634 \\ http://www.nber.org/papers/w14634 \\ NATIONAL BUREAU OF ECONOMIC RESEARCH \\ 1050 Massachusetts Avenue \\ Cambridge, MA 02138 \\ January 2009
}

We are grateful to Patricia Danzon, Richard Frank, Scott Harrington, Sean Nicholson, Mark Pauly, Stephen Propper, Fiona Scott-Morton, Steven Teutsch and participants at the 2nd American Society of Health Economists meetings and the 2008 annual meeting of the Southern Economic Association for helpful comments. Phil Saynisch provided exceptional research assistance. We would also like to acknowledge the Blanche and Irwin Lerner Center for Pharmaceutical Management Studies at the Rutgers University Business School for the IMS data. Financial support from the Merck Foundation to University of Pennsylvania is gratefully acknowledged. The views expressed herein are those of the author(s) and do not necessarily reflect the views of the National Bureau of Economic Research.

NBER working papers are circulated for discussion and comment purposes. They have not been peerreviewed or been subject to the review by the NBER Board of Directors that accompanies official NBER publications.

(C) 2009 by Guy David, Sara Markowitz, and Seth Richards. All rights reserved. Short sections of text, not to exceed two paragraphs, may be quoted without explicit permission provided that full credit, including $\odot$ notice, is given to the source. 
The Effects of Pharmaceutical Marketing and Promotion on Adverse Drug Events and Regulation Guy David, Sara Markowitz, and Seth Richards

NBER Working Paper No. 14634

January 2009

JEL No. I1,K0,K2

\begin{abstract}
$\underline{\text { ABSTRACT }}$
This paper analyzes the relationship between postmarketing promotional activity and reporting of adverse drug events by modeling the interaction between a welfare maximizing regulator (the FDA) and a profit maximizing firm. In our analysis demand is sensitive to both promotion and regulatory interventions. Promotion-driven market expansions enhance profitability yet may involve the risk that the drug would be prescribed inappropriately, leading to adverse regulatory actions against the firm. The model exposes the effects of the current regulatory system on consumer and producer welfare. Particularly, the emphasis on safety over benefits distorts the market allocation of drugs away from some of the most appropriate users. We then empirically test the relationship between drug promotion and reporting of adverse reactions using an innovative combination of commercial data on pharmaceutical promotion and FDA data on regulatory interventions and adverse drug reactions. We provide some evidence that increased levels of promotion and advertising lead to increased reporting of adverse medical events for certain conditions.
\end{abstract}

\author{
Guy David \\ Health Care Management Department \\ The Wharton School \\ University of Pennsylvania \\ 204 Colonial Penn Center \\ 3641 Locust Walk \\ Philadelphia, PA 19104-6218 \\ gdavid2@wharton.upenn.edu \\ Sara Markowitz \\ Department of Economics \\ Emory University \\ Rich Building, 3rd floor \\ 1602 Fishburne Dr. \\ Atlanta, GA 30322 \\ and NBER \\ sara.markowitz@emory.edu
}

\author{
Seth Richards \\ Department of Economics \\ University of Pennsylvania \\ 3718 Locust Walk \\ Philadelphia, PA 19104 \\ serichar@econ.upenn.edu
}




\section{Introduction}

Pharmaceutical drug regulation has a long history in the United States, dating back to 1906 with the passage of the Pure Food and Drug Act. Over the years, the regulatory powers of the Food and Drug Administration (FDA) have expanded, beginning first with the charge to monitor drug safety, and later, to monitor the efficacy of drugs. However, the major legislation affecting and defining the FDA has focused primarily on premarket safety and efficacy. Even recent legislation designed to speed the approval time for new drugs ignored postmarketing surveillance until 2002, when limited funds were specifically designated for this purpose (IOM 2007).

Events in the late 1990s and early 2000s spawned a new call for regulation that focuses on postmarket safety. Between 1997 and 2005, eighteen drugs were withdrawn from the market, compared to only nine withdrawals in the previous twenty years (USFDA 2005). Many of these withdrawals were highly publicized, including those for the appetite suppressant Fenfluramine (withdrawn in 1997) and the cholesterol reducing drug Cerivastatin (withdrawn in 2001). Also during this time period, numerous drugs in two major classes (NSAIDs and antidepressants) had black box warnings added to their labels (IOM 2007). The 1992 Prescription Drug User Fee Act, which sped up the approval time for new drugs, has been implicated as a cause of such safety problems (Olson 2002; Rudholm 2004). All of these factors helped to create the appearance of decreased safety of drugs, and lead to a series of new recommendations by the Institute of Medicine (IOM) to improve the oversight abilities of the FDA (IOM 2007). ${ }^{1}$ A major component of the IOM report calls for improvements in the postmarketing surveillance of drugs,

\footnotetext{
${ }^{1}$ Note that the approval date for seven of the recent drugs withdrawn was prior to 1997, implying that the increased numbers of withdrawals could reflect improved postmarket surveillance.
} 
along with restrictions on labeling and direct-to-consumer advertising (DTCA), and legislation to give the FDA new postmarket enforcement authority.

The need for postmarketing surveillances is underscored by the inherent uncertainty that arises when a new drug enters the market. The randomized control trials used by the FDA to approve new drug applications are considered to be the gold standard for demonstrating the efficacy of drugs. However, the postapproval effectiveness of drugs is unclear since clinical trials do not mimic "real world" conditions for a variety of reasons. First, individuals represented in the clinical trials may be very different from those in the postapproval population. In an article for the New York Times Magazine, Gary Taubes explains the problem:

"Clinical trials invariably enroll subjects who are relatively healthy, who are motivated to volunteer and will show up regularly for treatments and checkups. As a result, randomized trials 'are very good for showing that a drug does what the pharmaceutical company says it does,' David Atkins, a preventive-medicine specialist at the Agency for Healthcare Research and Quality, says, 'but not very good for telling you how big the benefit really is and what are the harms in typical people. Because they don't enroll typical people."” (Taubes 2007. p 56)

The IOM reports that clinical trials often exclude people with co-morbid conditions and who use other drugs concurrently. Also, those who are elderly and ethnic minorities tend to be underrepresented in the trials (IOM 2007).

A second problem is that of sample size, where rare adverse events are difficult, if not impossible, to detect in clinical trials if they occur at rates that are too small. Evaluating the effects of long-term exposure to the drug is another problem since most clinical trials are relatively short lived. Lastly, the implications of off-label use (where the drug is used for treating a different condition than that for which it was approved) are unknown. Such use 
creates a 'new' population with potentially different risk-benefit profile. All of these factors highlight the need for postmarketing surveillance.

Uncertainty regarding the postmarket risks of a new drug goes along with uncertainty of the postmarket benefits. Currently, the FDA carefully weighs the risks and benefits as part of the process of approving new drugs. However, postapproval, consideration of benefits is dramatically diminished by the agency. Part of the problem is that outside of controlled experiments, drug benefits are difficult to assess in the general population. Even in the cases where a phase 4 clinical trial (i.e. a postapproval trial) has been agreed upon prior to approval, the FDA has no power to ensure that it is conducted.

Postapproval, manufacturers have the incentive to expand the population of users by advertising and promoting the new drug. Indeed, the amount of money spent on such activities has been steadily increasing since the mid 1990s, with nominal expenditures rising from about \$9.1 billion in 1996 to over \$26 billion in 2004 (Brichacek and Sellers 2001; Lam 2004). Promotional activities aimed at health professionals make up the bulk of expenditures, although the share of DTCA has risen steadily over time. DTCA spending was $\$ 790$ million in 1996 (8.6 percent of the total), rose to $\$ 3.45$ billion in 2004 (13.2 percent of the total) and by 2006, reached over $\$ 4.8$ billion or 18.3 percent of total promotional spending (Brichacek and Sellers 2001; Lam 2004; West 2007). Much of this growth can be attributed to new television and magazine advertising that emerged after the FDA changed the regulations regarding advertising in $1997 .^{2}$

Promotional activities by pharmaceuticals are controversial practices. On the professional side, pharmaceutical companies reach out to physicians through a variety of means

\footnotetext{
${ }^{2}$ Prior to 1997, firms could either advertise the condition with no mention of the drug's name or advertise the drug's name with no mentionffgr of the condition. These restrictions were lifted in 1997 allowing the firm to establish a link between the drug advertised and the condition it treats, and hence to improve the effectiveness of their advertising.
} 
including detailing (meetings with sales representatives), gifts, free samples, trips to conferences, sponsorship of educational events, and advertising in medical journals (Buckley 2004). The benefit of these practices is, of course, the new information that is conveyed to physicians, but many less desirable outcomes have also been associated with professional promotion. In a review of 16 studies, Wazana (2000) finds that interactions with pharmaceutical companies are associated with the following: 1) formulary addition requests for the sponsored drug that are not clearly advantageous to the existing formulary drugs; 2) prescribing practices in favor of the sponsored drug; 3) a preference for, and rapid prescribing of new drugs; 4) a decrease in prescribing of generic drugs in favor of newer medications with no apparent advantages.

Economists have also studied the implications of detailing and other promotional activities on the size of the market, market shares among firms, and the physician's price elasticity of demand. Recent studies by Rizzo (1999) and Windmeijer et al. (2006) have examined these questions in detail. These authors find that the presence of promotion reduces the price elasticity of demand for prescribed drugs implying that social welfare is harmed by reduced price competition and higher prices. Windemeijer et al. (2006) also find that promotion primarily expands market share, while Rizzo (1999) finds evidence that promotion expands the size of the market.

The increased DTCA has also lead to a debate on the effects of this advertising. Research has shown that DTCA is associated with increases in spending on prescriptions drugs and utilization, the number of visits to doctors, and prescribing rates (GAO 2002; Bradford et al. 2006; Iizuka and Jin 2005; Donohue et al. 2004), but the question is, what are the implications of the increased drug use. Researchers have identified a number of pros and cons. On the plus side, DTCA has the potential to educate people about certain conditions, encourages them to 
seek professional help, and may result in the receipt of treatment that they otherwise would not have (Masson and Rubin 1985; Lyles 2002; Chao 2005; Almasi et al. 2006). Although Bell et al. (2000) fail to find educational value in DTCA. Limited evidence also shows that DTCA may encourage patients to adhere to drug therapies (Calfee et al. 2002; Donohue et al. 2004; Wosinska 2004) and protects against undertreatment (Kravitz et al. 2005). Note that Donohue et al. (2004) also find that unlike DTCA, spending on detailing has no effect on the duration of appropriate drug treatment.

On the down side, the concern with DTCA is that the rapid uptake of new drugs may not necessarily be better than the existing drugs, and problems may arise when the new uptake is among patients who are not a good match for the drug (Spence et al. 2005; Kravitz et al. 2005). Because of the potential for mismatch, pharmaceuticals represent an unusual case where advertising may not be unilaterally welfare enhancing when it expands the size of the market (Berndt 2006). ${ }^{3}$ In addition, DTCA may encourage use of the newer, more costly drugs at the expense of less costly drugs that are equally effective (Spence et al. 2005; Kravitz et al. 2005).

Absent any regulation, a profit maximizing producer has no incentive to improve the quality of the match by altering the level of promotion. However, under the current system, firms may be penalized for creating a mismatch between patients and drugs on the basis of safety. ${ }^{4}$ Therefore, even a profit maximizing firm has to balance the expansion of its product with the risk of unfavorable regulatory action stemming from a decreased quality of the match of drugs to patients. Such regulatory intervention from the FDA may include labeling changes, safety warnings, or even the removal of the product from the market. While the risk of

\footnotetext{
${ }^{3}$ When DTCA does not expand the market and only affects market shares, brand switching among consumers will be welfare enhancing when it improves the match. However, the current literature shows that DTCA is primarily market expanding (Narayanan et al. 2004; Iizuka and Jim 2005)

${ }^{4}$ Note that when the regulatory system focuses on safety, firms have little incentive to improve the quality of the match on the basis of the benefit to patients.
} 
regulatory intervention increases with adverse events, the FDA's reaction relies on signals generated from reported adverse events, which is an inherently noisy signal. All of these factors must be considered by the firm.

This paper examines the incidence of adverse drug events associated with pharmaceutical promotion and the relationship between adverse events and regulatory action by the FDA. To do so, we present a newly developed theoretical framework that explicitly addresses the interaction between firms and their regulator, while incorporating the FDA's problem of poor signal quality. This framework then guides an empirical analysis of adverse events, which examines two parts of the connection between pharmaceutical promotional activities and the FDA. The first seeks to answer the question of whether increased levels of promotion lead to a worsening match of drugs with patients and lead to increased reporting of adverse medical events. The second seeks to measure the degree to which increased reported adverse events leads to FDA actions.

There has been surprisingly little research on the factors influencing the safety of drugs, and much of this research has examined the influence of approval time. Part of the problem with doing so is identifying appropriate measures of safety. Withdrawals are a rare event and therefore are difficult to analyze. Rawson and Kaitin (2003) is one of the few studies to analyze withdrawals. In a cross-country comparison, they find that longer drug approval times in Canada resulted in fewer market withdrawals as compared to the United States during the period 19922001. They conclude that the delay in approval allowed Canadian patients to avoid exposure to potentially dangerous drugs. Berndt et al. (2005) also analyze drug withdrawals in the U.S., and find that changes in approval times brought about by the Prescription Drug User Fee Act of 1992 did not result in increases in the proportion of drugs withdrawn from the market. 
A few other studies have examined the question of whether the speed at which drugs are approved has resulted in increased adverse drug reactions (ADRs). In the U.S., Olson (2002) uses the Spontaneous Reporting System of adverse drug reactions (the predecessor to the current system, the Adverse Event Reporting System), and analyzes counts of ADRs for new drugs approved between 1990 and 1995 . The models controls for therapeutic novelty, therapeutic category of drug, log of utilization (the number of prescriptions estimated from MEPS), an indicator if the drug is an orphan drug, average patient characteristics (age and gender). Olson finds that shortened review times are associated with more ADRs that resulted in hospitalization and death. Rudholm (2004) conducts a similar analysis for drug approvals in Sweden. After controlling for the quantity sold of the drug, random effects in therapeutic class, and other factors related to regulation in Sweden, the author finds that shorter approval times are associated with increased ADRs. In their conclusions, both authors warn that there is a tradeoff between increased ADRs and increased access to treatments that must be considered.

Therapeutic novelty may also be a determinant of ADRs. As Olson (2002, 2004) describes, these drugs, which are the first in their class, may have more adverse events than older drugs for number of reasons. First, doctors and patients are inexperienced with these drugs and this may result in more adverse events. Second, the patients who receive the drugs may be sicker and more susceptible to adverse events. Third, reviewers at the FDA may be more willing to accept risk in order to expedite the approval of the new drugs. In an empirical analysis, Olson (2002, 2004) finds that drugs designated as novel are associated with a higher incidence of ADRs. The implication for our research here is that these novel drugs may be more heavily advertised and detailed than other drugs, meaning they may be overrepresented in the data (Olson 2002). 
The paper proceeds as follows: section II presents a model of promotion and safety, in which a drug manufacturer chooses price and promotion and a regulator chooses regulatory actions that may impact the demand for the drug. Section III describes the data and estimation, sections IV and V discusses the results, and section VI concludes.

\section{A Model of Promotion and Safety}

This model puts a theoretical foundation around the interactions between the FDA and pharmaceutical firms in terms of promotion and safety activities. Once a drug is approved for use, a welfare maximizing bureaucrat (i.e., the FDA) and a profit maximizing drug manufacturer engage in a game. The FDA, having the power to withdraw a drug from the market (or reduce its demand through labeling restrictions and warnings), will offer the firm a scheme specifying regulatory actions based on signals from persons taking the drug. The firm maximizes expected profits by expanding the number of prescriptions filled. The safety and benefit profile of people receiving the drug changes as demand for drug expands. Demand is affected by promotional activities, which increase both revenues and the chance of a poor match between patients and the

drug. A crucial aspect of the model is that regulation depends on distorted information about the utility impact of a drug, so we can analyze the effect of an overemphasis on drug safety as compared with the actual balance of safety and benefit.

We consider the simplest case, in which the firm is a monopoly, it produces only one drug (or the profits derived from different drugs are entirely separable), and the drug can treat only a single health problem. Under these assumptions the promotional activity taken by a firm has no effect on other firms. Hence, the relationship between the FDA and pharmaceutical firms 
can be reduced to an interaction between the agency and a single firm. In addition, we assume the FDA attempts to maximize social welfare conditional on initially approving a drug.

We begin by specifying utility over two dimensions: safety and benefit. We relate this to a demand function for the drug which is mediated by physicians and influenced by promotional activities. We then turn to the FDA problem and derive the welfare maximizing regulatory rule, which relies on safety signals from persons taking the drug. The firm, in turn, chooses promotion to maximize expected profits incorporating the FDA's regulatory rule. Unlike existing models of promotion under uncertainty, the firm's choice of promotional activity affects the risk exposure to unprofitable regulatory interventions.

\section{Utility and Appropriateness}

We model utility using a two-dimensional space of safety and benefit, as shown by Figure 1.1. The two dimensions allow for misaligned incentives or distorted information in the regulatory process, and in particular, address the difficult task faced by the FDA of balancing safety with efficacy when it considers regulatory actions. In the space, individuals are located throughout the unit square, meaning that the health benefit of a drug and its safety range from 0 to 1 , and the gray circle represents the highest level of benefit and safety attainable. ${ }^{5}$ Under our assumption that each drug is relevant only for a single health problem, individuals have only one position in the safety-benefit space.

Our measure of utility then comes from the concept of the "appropriateness” of a drug for an individual patient, which refers to an assessment of the balance between its potential risks and benefits to that patient. Appropriateness reduces the safety - benefit tradeoff to a single distance measure, so people with different positions in the space may have the same utility. For example,

\footnotetext{
${ }^{5}$ A person located at $(1,1)$ will experience the maximum health benefits and minimal risk of an adverse reaction.
} 
a sick but relatively fragile person who stands to benefit substantially from the drug but has serious risk of harmful side effects or interactions (position B) could have the same expected utility as a more healthy person who also has the condition but would recover eventually without the drug (position C). Position A represents the same health benefit as position B yet higher safety. Similarly, a person in A has the same safety level as one in C yet higher health benefits. Therefore, we say that the drug is more appropriate for a person in position A than it is for either persons in positions B and C.

\section{[FIGURE 1]}

We use the Euclidean distance from the optimal match at $(1,1)$ to measure the appropriateness of using a drug. Specifically, a person with $b$ potential benefit and $s$ potential safety would have an overall effect that is $z=\sqrt{(1-b)^{2}+(1-s)^{2}}$ less than the optimum. Thus we can think of $z$ as the difference in appropriateness for an individual, compared with the best possible match for the drug. Each level of $z$ produces an iso-appropriateness curve in the benefitsafety space. Utility then depends on the value of the drug at the optimal match, which we denote $\beta$. We assume $0<\beta<1$ so that no drug could benefit the entire population, even absent any safety concerns. Subtracting individual appropriateness from the highest attainable value for the drug in the population gives the expected utility for an individual $i$ taking the drug, so $u_{i}=\beta$ $z_{i}$. Since $\beta<1$, a person with $(b, s)=(0,0)$ will have negative utility from the drug as $\beta-z_{0,0}=1-\sqrt{2}<0$. Zero utility is reached when $b=\beta-\sqrt{s(2-s)^{2}}$.

By specifying the distribution of individuals within the safety-benefit space, a demand function can be derived (see Appendix A for the case of joint uniform distribution). 


\section{Promotion and Demand}

Our notion of promotion is very general-it encompasses everything done by the firm to affect demand and perceptions of its drug, not just paid advertising or other easily observed and audited activities. This helps to explain why the FDA puts little emphasis on regulating promotional activities directly.

Both physicians and consumers respond to promotional activities, which largely take the form of detailing and direct-to-consumer advertising. We assume physicians will only prescribe drugs that are sufficiently appropriate for their patients, so they have a threshold $\underline{z}$ and will only prescribe the drug to individuals with $z_{i} \leq \underline{z}$. This $\underline{z}$ responds to promotion (e.g., detailing) because physicians update their beliefs regarding the safety and benefits associated with the drug. As for the effect of promotion on consumers, we assume DTCA makes more patients seek treatment for the health problem as it increases the value that all consumers place on the drug, so marginal patients will choose to visit a doctor. Additionally DTCA makes patients more insistent that they be treated. ${ }^{6}$ Because physicians wish to satisfy their patients, they will adjust $\underline{Z}$ indirectly due to DTCA (Mintzes et al., 2002).

In addition to expanding the frontier of potential consumers represented by $\underline{z}$ (extensive margin), our demand formulation allows for promotion to increase the number of individuals within the frontier who are treated by the drug (intensive margin). This occurs when consumers with the same level of appropriateness for the drug are heterogeneous in their response to promotion and/or when firms improve match quality by learning to better target appropriate users. This is consistent with Kravitz et al. (2005) who find that patients' requests for antidepressants, following DTCA, had a profound effect on physician prescribing. We assume

\footnotetext{
${ }^{6}$ DTCA also makes patients more likely to request a particular drug among a set of options, but this goes beyond the monopoly setting in the model.
} 
that the net effect of promotion is to lower the average match quality among users. Our assumption holds whenever the intensive margin effect is driven primarily by exposure to promotional activity and has little to do with the individual's appropriateness level.

We assume that physicians accurately understand the tradeoff between benefit and safety as they affect patient utility. This means that promotion activity which targets a single aspect (say, benefit) would impact the entire frontier in the $(b, s)$ space. Updating beliefs about the benefits of a drug corresponds to its perceived appropriateness. The more beneficial a drug is, the greater is the willingness to prescribe it to patients with higher risk. This tradeoff does not require promotion activity to target physicians directly (i.e. detailing). ${ }^{7}$

The idea that individual physicians can assess the appropriateness level of a drug relies on the notion that physicians are able to identify accurately each individual's address on the safety-benefit space (similar to Brekke and Kuhn, 2006). The risks involved with taking a drug depend on a large number of factors that include demographics, lifestyle, family history, health conditions and other drugs in use. Physicians who are faced with drug prescribing decisions will eventually take this complex multi-dimensional risk space, even if not explicitly, and collapse it in some fashion to guide their decision making process. For tractability we assume that risk can be condensed into a single index. Learning over time about the various risk factors for a specific drug calls for repeated updating of each individual's location on the benefit-safety space. While our formulation rules out dynamic improvements in match-quality by learning about the impact of risk factors, for the purpose of our empirical analysis, this assumption is conservative insofar as any such learning will weaken the relationship between promotional activities and reporting of adverse events.

\footnotetext{
${ }^{7}$ If direct-to-consumer advertising alters patients' perception of the health benefits of a drug, patients still need to communicate this belief to their physician, who then makes the tradeoff between benefits and safety and adjusts $\underline{z}$.
} 
Moreover, absent from our model is the notion that promotion can be effectively tailored to sub-populations defined in terms of safety or benefit. Firms would benefit from switching a high benefit - high risk individual with a low benefit - low risk individual, even when the drug is more appropriate for the former (i.e. replacing individual $A$ in Figure 1.1 with individual $C$ ). The reason is that the incentives provided by the regulator tracks safety closer than it tracks benefits. This behavior, that might be termed "defensive" tailoring, is consistent with both increasing the firm's expected profits and decreasing social welfare. While the notion of iso-appropriateness curves rules out defensive tailoring, it is important to notice that such tailoring of promotion activity would reduce the match-quality even further as it leads to replacing sicker individuals, in need of treatment, with healthier ones (i.e. lowering the average level of appropriateness). This highlights the regulatory problem of achieving incentive compatibility by relying on a single dimension - safety.

The expected demand function is given by $x=x(p, A, R)$, where, $p$ is the price of the drug and $A$ is the expenditure on promotion activities chosen by the firm. $R$ is an equilibrium regulatory rule. The effect of advertising on demand is given by $\frac{\partial x}{\partial A}+\frac{\partial x}{\partial R} \cdot \frac{\partial R}{\partial A}$. The first term is the direct effect of promotion on demand and the second term is the indirect effect of promotion on demand through its effect on regulatory action.

We make the standard assumption that demand is concave in promotion, which has implications for the distribution of utility and the effectiveness of promotion. Because in general fewer people have a condition that is treated by a drug than not, the density of individuals with small $z_{i}$ (highly appropriate) would be less than those with large $z_{i}$ (poor match). Hence the density of individuals would increase as $z_{i}$ increases. Therefore, for demand to be concave in 
promotion, it must become sufficiently more difficult to expand the frontier $\underline{z}$ to counter this increase in the density of potential consumers.

With regard to price, we assume that physicians are perfect agents for patients, and that they internalize the effect of price on consumer utility. An increase in price has two effects: the first is the usual lowering of the quantity demanded (through a reduction in the area under $\underline{z}$ ), the second, is improving the average match (appropriateness). This notion of conflicting welfare effects coincides with Ashraf, Berry and Shapiro (2007).

We further assume that with no promotion activity $z=z_{0}$; a small amount that represents the knowledge and perceptions of the drug among physicians (and to a much lesser extent, consumers) based on reports of clinical trials, FDA approval, and the drug's label. The assumption that demand would be small without any promotion can be motivated by the absence of pressure from patients, underrepresentation in hospitals' formularies, and risk aversion on the part of physicians, as uncertainty about the effect of a drug would reduce its expected value in this case.

\section{Consumer Welfare and the Regulatory Process}

Consumer welfare is maximized when the utility of the drug for users on the extensive margin $\left(z_{i}=\underline{z}\right)$ equals zero. For simplicity, we ignore the marginal cost of promotion, price and variable production cost. However, the qualitative results are similar. We also assume that the distribution of $Z$ is uniform, hence $x=Z$. The first best solution is attainable when the regulator observes promotion, $A$. In this case, the regulator's problem is

(3.1) $\operatorname{Max}_{A} \int_{0}^{Z(A)}(\beta-Z) d Z$,

with a first-order condition 


$$
Z\left(A^{*}\right)=\beta
$$

The demand function $\underline{Z}(A)$ is increasing and concave, so we have a unique interior solution. It is worth noting that whenever $\beta>Z(0)=z_{0}$, promotion is socially beneficial in our model because otherwise too few individuals would use the drug. There is a unique non-zero solution, yielding a socially optimal promotion, $A^{*}$, and corresponding $Z^{*}=Z\left(A^{*}\right)$.

\section{[FIGURE 2]}

When first best is not attainable (i.e. the FDA does not observe $z$ or $A$ ). The FDA monitors the market and may take a regulatory action, denoted $R$, which the firm perceives as partially affected by its choice of price and promotion expenditures and partly a random variable. The effect of regulation can be modeled through the demand function, $z(p, A, R)$, and is decreasing in $R$. For example, in the case of drug withdrawal, $R$ is an indicator allowing for two states: withdrawal $z(p, A, 1)=0$; and no withdrawal. Warnings or restrictions on product labeling, which are common yet less severe regulatory actions, are represented by a safety level cutoff point, i.e. individuals with $s<\tilde{s}$ will be advised not to use the drug (in this case the benefit dimension is not considered). Unlike withdrawal where the drug is removed from the market and patient access is blocked, re-labeling will not be totally effective so some fraction of people, $\theta$, with $s<\tilde{s}$ but $z<\underline{z}$ will still receive the drug. Interestingly, effective product labeling (i.e. small $\theta$ ) could serve to shield the firm against drug withdrawals in a manner similar to “defensive” tailoring.

The action $R$ depends on a signal the FDA receives from the market based on its monitoring process. In a perfect world, the FDA would see the utility each user derives from the drug, i.e. $\beta-z_{i}$, and take action if $\beta-z<u^{*}$, where $u^{*}$ is a cutoff defined by the social planner's 
problem. However, the FDA does not observe the universe of prescribing decisions made by physicians and therefore is unable to elicit $z$. Instead, the FDA relies on adverse drug events reporting to produce a signal for regulatory actions. While the signal is imperfect, it is informative in that the probability of a bad signal increases as the average appropriateness of using a drug among all users decreases. The signal depends, in part, on the firm's promotion activities and in part is random.

Since the FDA relies primarily on adverse drug events reporting from patients, its information about the value of the drug to consumers is noisy and the signal extraction process is bound to overemphasize safety. The probability that a report will be received (and accepted) from each person taking the drug depends on a weighted version of their appropriateness measure. This constitutes a departure from the concept of appropriateness discussed earlier. Instead of appropriateness level the FDA identifies a signal from its Adverse Event Reporting System. The AERS signal is defined as: $S=z(A)+\varepsilon$. For tractability, we model the uncertainty in the system by including a mean-zero error term, $\varepsilon$.

The Adverse Event Reporting System used by the FDA is set up to receive reports of adverse events, not benefits. More generally, the FDA’s mission has historically been consumer protection from unsafe products rather than the evaluation of benefit-risk tradeoffs, so we could expect the agency to emphasize safety information when evaluating event reports. On the patient side, we believe individuals are more likely to report an adverse reaction the smaller the benefit that he or she has from the drug. Thus the probability of reporting summarizes a multi-step process: (1) an adverse event occurs with a probability that depends only on the individual's address along the safety dimension, $s$, and the drug's maximum value $\beta$; (2) the patient may or 
may not report this depending on the level of benefit from the drug; ${ }^{8}$ and (3) the FDA evaluates the report and decides whether to count it, favoring the safety information but considering the benefit as well. ${ }^{9}$

For simplicity, we assume that all reports have identical informational value once they are counted. Clinical trials, due to the small number of participants, can only detect common side-effects. Rare and potentially serious side-effects require a large population base, and only once a drug is approved for marketing is a large population base obtained. However, this is no longer a controlled study and establishing a causal link between using the drug and the reported side-effect is difficult to make. This uncertainty means that the number of reports is expected to change proportionally with the number of prescriptions filled for drugs with an identical risk profile. Therefore, we assume that the FDA is interested in the number of reports relative to the number of drug users, which is simply the expectation of $S$.

The FDA uses the signal, $S$ as an input into its regulatory action $R$. From a policy perspective, investment in improving signal extraction as a guide for regulatory action is costly and can take two general forms: (1) investment in system design to weight correctly the risks and benefits of the drug, and (2) investment in reducing measurement errors. The FDA would communicate to the firm the mapping of signal levels into regulatory actions.

\section{The Firm's Problem}

We model the postmarketing interaction between the firm and the FDA as one-shot a sequential game. This is a simplification as we leave out various types of iterative dynamics such as learning, reputation building, reinvestment of profits, etc. High promotional expenditure will

\footnotetext{
${ }^{8}$ For example, a patient may decide to report minor side-effects if the drug she takes is useless and ignore these side-effects if the drug adequately treats the condition for which it was originally prescribed.

${ }^{9}$ For example, reports of side effects that appear on the drug label will have very little informative content.
} 
raise demand for the drug but will also lower the average appropriateness of the drug for its population of users. In turn, poorer match between patients and the drug will increase the likelihood of unfavorable regulatory intervention. In other words, the firm faces uncertainty which it can mitigate or reinforce with its choice of promotion level.

For a safety signal to exist, individuals must purchase and experience the drug first and therefore generate initial revenue for the firm. While it is plausible that profits made by the firm initially (before the signal is formed) are important we will assume that the signal is formed fast enough such that a hit-and-run strategy is never profitable (mainly due to the high R\&D costs). Therefore we model the signal formation as instantaneous and ignore initial profits. Alternatively, this is also consistent with the idea that initial profits are competed away if regulatory action is taken (e.g. costly lawsuits that follow a decision to withdrawal a drug).

To fix ideas, we carry through the standard Dorfman-Steiner analysis, the firm’s revenue is given by $x(p, A, R) \cdot p$. Quantity decreases with price and increases with promotion. The Dorfman-Steiner rule for the monopoly case with no uncertainty is: $\frac{A}{p \cdot x}=-\frac{\varepsilon_{x, A}}{\varepsilon_{x, p}}$, where the lefthand term is the advertising-to-sales ratio, a common industry measure of advertising intensity, and $\varepsilon_{x, A}$ and $\varepsilon_{x, p}$ are the elasticity of advertising and the elasticity of demand, respectively. The advertising-to-sales ratio is positively associated with the demand responsiveness to advertising and negatively associated with the firm's market power. ${ }^{10}$ In addition to the low demand elasticity in medical markets, it has been shown that physicians and consumers respond to pharmaceutical promotion. As a result, the large expenditures on drug promotion are consistent

\footnotetext{
${ }^{10}$ Patent protection for their medicines often results in market power for pharmaceutical firms.
} 
with this modeling approach, although the original Dorfman-Steiner model incorporates neither uncertainty nor regulation.

Similar to Horowitz (1970), Dehez and Jacquemin (1975), and Brick and Jagpal (1981), who introduced uncertainty to the advertising framework, the pharmaceutical firm maximizes expected profit by choosing price and promotion expenditures: ${ }^{11}$

$$
\underset{p, A}{\operatorname{Max}}(1-w(p, A)) \cdot[x(p, A) \cdot(p-c)]-A
$$

Where $w(p, A)$ is the probability that a drug is withdrawn from the market. We use monopoly profits because firms are awarded patents for the drugs they develop, during which time no other firm can legally produce the patented pharmaceutical.

Taking the ratio of the first-order conditions with respect to price and the first-order conditions with respect to promotion and multiplying both sides by $A / p$ yields the modified Dorfman-Steiner condition.

$$
\frac{A}{(1-w) \cdot p \cdot x}=-\frac{(1-w) \cdot \varepsilon_{x, A}-w \cdot \varepsilon_{w, A}}{(1-w) \cdot \varepsilon_{x, p}-w \cdot \varepsilon_{w, p}}
$$

Where $\varepsilon_{x, p}$ is the elasticity of demand and $\varepsilon_{x, A}$ is the elasticity of advertising. $\varepsilon_{w, p}$ and $\varepsilon_{w, A}$ represent the sensitivity (as an elasticity) of the regulatory action (in this case: withdrawal) to the firm's price and advertising expenditures, respectively (for derivation of 4.2 see Appendix B). This expression is nonstandard because it includes the indirect effect of prices and promotion on profits via the probability of regulatory action. In essence, increasing promotional activities

\footnotetext{
${ }^{11}$ Note that from this point on, we make the simplifying assumption of constant marginal costs, $c$.
} 
trades off higher likelihood of profit-lowering regulatory actions with higher profits in the case that such regulatory action is not taken.

This modified rule suggests that the expected advertising-to-sales ratio is a weighted average of demand, advertising, and regulatory elasticities, with the weights being the probability of withdrawal, $w(p, A)$. Note that the modified rule in (4.2) always yields a lower advertising-to-sales ratio relative to a Dorfman - Steiner rule with an exogenous probability of withdrawal.

An implication of (4.2.) is that a higher elasticity of promotion leads to higher expenditures on promotional activity and a higher advertising-to-sales ratio. The modified Dorfman - Steiner rule in (4.1) yields lower expenditures on promotion activity relative to a model with (exogenous) uncertainty and even lower expenditures on promotion activity relative

to the original Dorfman - Steiner rule such that $\left.A\right|_{w(p, A)=0}>\left.A\right|_{w(p, A)=\hat{w}}>\left.A\right|_{w(p, A)}$. This is true for the advertising-to-sales ratio as well. One way to think about this is that the marginal cost of promotion is higher when uncertainty is endogenous, as additional advertising spending will increase the likelihood of adverse regulatory action.

\section{Timing}

The timing of the game is as follows: in period 1 the FDA chooses a rule of the form $w(A)=m \cdot S(A)=m \cdot(z(A)+\varepsilon)$, where $m$ is a parameter that the FDA announces to the firm. To keep the exposition simple, we assume that the FDA cannot later renege on the choice of $m$. This choice of parameter is ex-ante efficient when price and promotion are more important than $\varepsilon$ in producing the signal $S$. If containing $A$ has little effect on the match-quality there is not 
much use for regulation. Similarly, when the signal is very noisy the FDA will have little benefit from using the AERS.

In period 2, the firm observes the regulatory rule and incorporates it into its expected profit function, used to derive the price and promotion expenditures, and the latter are paid at this time, as in (4.1). The firm choice will determine the number of users and their safety-benefit profile.

\section{Timing of the Game}

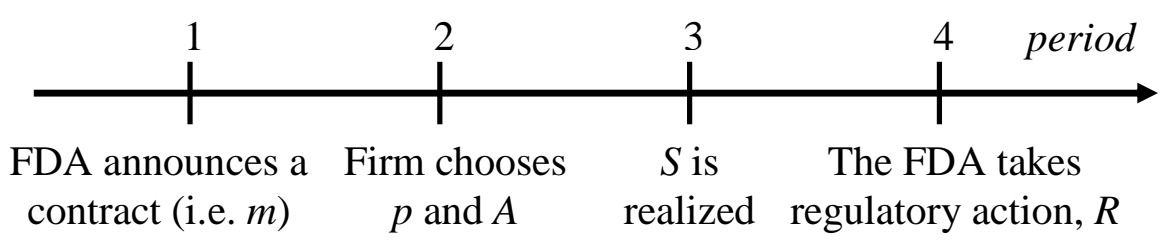

In period 3, some users, based on their safety-benefit location and the true maximal value of the drug, $\beta$, will report adverse drug events to the FDA to form a reporting signal with noise. In period 4 the signal is observed by the FDA and translated into a regulatory action according to its pre-specified rule, $w(A)$. Finally, the firm's true profits are realized.

\section{Equilibrium Predictions and Comparative Statics}

For simplicity, we assume the producer takes prices as given such that the markup is constant. The demand function simplifies to $z=\alpha \cdot Z(A) \cdot(p-c)$, where $\alpha$ is a parameter capturing market size for the drug. First, we consider the case where firms only choose promotion levels, $A$, and where promotion maps into $Z$. 
In the simplest case, the FDA would communicate the probability of regulatory action $w(A)=m \cdot S=m \cdot[Z(A)+\varepsilon]$ for any signal, $S$ from the AERS. The penalty weight, $m$, will determine the firm choice of promotion level.

The firm maximizes expected profits subject to the probability of regulatory action being between 0 and 1:

$$
\begin{aligned}
\operatorname{Max}_{Z, i} & (1-m \cdot E[Z(A)+\varepsilon]) \cdot(\alpha \cdot Z(A) \cdot(p-c))-\gamma \cdot \frac{Z(A)^{2}}{2}-\frac{i^{2}}{2} \\
& \text { s.t. } 0 \leq m \cdot E[Z(A)+\varepsilon] \leq 1
\end{aligned}
$$

We assume the cost of promotion is convex with $\gamma$ capturing the effectiveness of promotion. We introduce $i$, an investment made by the firm in postmarketing surveillance and allocating resources to analyze signals from the adverse event reporting system. When $i$ is not incorporated into the signal received by the FDA, the firm has no incentive to invest in $i$. This result changes when the FDA incorporates input from the firm into its regulatory rule.

The first order conditions are:

$$
Z^{*}=\frac{\alpha \cdot(p-c)}{\gamma+2 m \cdot \alpha \cdot(p-c)}
$$

(6.3) $i^{*}=0$

$Z^{*}$ is the best response function to any level of $m$ chosen by the regulator. The FDA will use $Z^{*}$ in its consumer welfare maximization:

$$
\operatorname{Max}_{m}\left(1-w\left(m, Z^{*}\right)\right) \cdot \int_{0}^{Z^{*}(m)}(\beta-Z) d Z=\left(1-w\left(m, Z^{*}\right)\right) \cdot\left[\beta \cdot\left(\frac{\alpha \cdot(p-c)}{\gamma+2 m \cdot \alpha \cdot(p-c)}\right)-\frac{\left(\frac{\alpha \cdot(p-c)}{\gamma+2 m \cdot \alpha \cdot(p-c)}\right)^{2}}{2}\right]
$$

$$
\text { s.t. } E[\pi] \geq 0
$$

The first order condition with respect to $m$, is: 
(6.5) $m=\frac{\alpha \cdot(p-c)-4 \beta \cdot \gamma+\sqrt{4 \beta^{2} \gamma^{2}+2 \beta \cdot \gamma \cdot \alpha \cdot(p-c)+\alpha^{2} \cdot(p-c)^{2}}}{4 \beta \cdot \alpha \cdot(p-c)}$

Comparative statics yields unambiguous signs on all five parameters, such that:

$\frac{d m}{d c}<0 ; \frac{d m}{d p}>0 ; \frac{d m}{d \alpha}>0 ; \frac{d m}{d \beta}<0 ; \frac{d m}{d \gamma}<0$

The FDA is more likely to use the AERS signal when production costs are lower, price is higher, market size for the drug application is larger, the value of the drug is lower and the effectiveness of promotion is small.

Thus far we assume that the signal extraction is costless. In reality, the infrastructure needed to assess the safety of drugs postmarketing is costly and claims resources. While the question of whether the cost of investing in FDA-based drug studies postlaunch is justifiable on economic grounds is debatable, an alternative regime exists. The FDA can charge the firm with the task of engaging in postmarketing surveillance. Under this regulatory mechanism, the FDA does not extract an independent signal from the AERS, instead the FDA induces the firm to invest in postmarketing surveillance by relying solely on a signal produced by the firm. This signal takes the form $S(A, i)=Z(A)-i+\mu$. Where, $Z(A)$ is the true level of appropriateness, $i$ is a firm-specific bias in interpretation, and $\mu$ is a mean-zero error term, potentially with smaller variance than $\varepsilon$, due to less costly and more effective surveillance. The FDA observes $S$, but not its components. Under the new regulatory mechanism the firm is free to choose $i$ in addition to $Z$ in maximizing expected profits. Similar to the baseline case, the FDA will communicate a probability of regulatory action $w(A)=m \cdot E[Z(A)-i+\mu]$, where the penalty weight, $m$, will determine the firm choice of both postmarketing surveillance and promotion level.

The firm maximization problem is similar to (6.1): 


$$
\begin{aligned}
\operatorname{Max}_{Z, i} & (1-m \cdot E[Z(A)-i+\mu]) \cdot(\alpha \cdot Z(A) \cdot(p-c))-\gamma \cdot \frac{Z(A)^{2}}{2}-\frac{i^{2}}{2} \\
& \text { s.t. } 0 \leq m \cdot E[Z(A)-i+\mu] \leq 1
\end{aligned}
$$

The first order conditions with respect to $i$ and $Z$ are: $i=m \cdot[Z \cdot \alpha \cdot(p-c)]$ and

$$
Z=\frac{(1+m \cdot i) \cdot \alpha \cdot(p-c)}{\gamma+2 m \cdot \alpha \cdot(p-c)}, \text { respectively. }
$$

First, note that for any $m>0$, investment in postmarketing surveillance is positive. Two components govern the level of investment in $i$ : (1) the importance that the FDA will place on communications with the firm, $m$, and (2) the profit that the firm makes if the drug is not withdrawn from the market (i.e. the importance of the drug to the firm). This would also mean that when the FDA commits to incorporating input from the firm, the firm will choose a higher promotion level (resulting in a higher equilibrium $Z$ ).

Solving for $Z$ and $i$ as a function of parameters and the FDA's weight penalty choice, $m$, results in two best-response functions for the firm.

$$
\begin{aligned}
& Z^{*}=\frac{\alpha \cdot(p-c)}{\gamma+2 m \cdot \alpha \cdot(p-c)-m^{2} \cdot \alpha^{2} \cdot(p-c)^{2}} \\
& i^{*}=\frac{m \cdot \alpha^{2} \cdot(p-c)^{2}}{\gamma+2 m \cdot \alpha \cdot(p-c)-m^{2} \cdot \alpha^{2} \cdot(p-c)^{2}}
\end{aligned}
$$

The FDA will use these responses to maximize consumer welfare over its choice of $m$.

$$
\operatorname{Max}_{m}(1-w(m, Z, i)) \cdot\left[\beta \cdot\left(\frac{\alpha \cdot(p-c)}{\gamma+2 m \cdot \alpha \cdot(p-c)-m^{2} \cdot \alpha^{2} \cdot(p-c)^{2}}\right)-\frac{\left(\frac{\alpha \cdot(p-c)}{\gamma+2 m \cdot \alpha \cdot(p-c)-m^{2} \cdot \alpha^{2} \cdot(p-c)^{2}}\right)^{2}}{2}\right]
$$

s.t. $E[\pi] \geq 0$ 
Similar to the original case, comparative statics yields the same unambiguous signs on all five parameters, such that:

$\frac{d m}{d c}<0 ; \frac{d m}{d p}>0 ; \frac{d m}{d \alpha}>0 ; \frac{d m}{d \beta}<0 ; \frac{d m}{d \gamma}<0$

However, the equilibrium consumer welfare, firm expected profits, penalty weights and probability of regulatory action would change. There is a social cost of delegating postmarketing surveillance to manufacturers. Under the firm-driven signal regime (compared with the FDAdriven signal regime) the average quality of the match between drugs and users deteriorate; the FDA will place a higher penalty weight on the firm's signal; the probability of regulatory action increases, but so is profitability conditional on survival; therefore, the effect on expected profitability is ambiguous. Even if the new regime results in lower profitability, choosing $i=0$ (i.e. mimicking the original case) is not optimal and therefore not credible.

The model shows how the key parameters (such as elasticity of promotion) lead to different equilibrium outcomes (such as the average match quality or the strictness of regulation). However, the relationship between underlying parameters and the amount of promotion and regulation may be ambiguous. A higher elasticity of promotion has both a direct effect of making promotion expenditures more profitable and an opposite indirect effect of making regulation more sensitive to the signal. Thus, there are offsetting effects for the relationship between the elasticity of promotion and the likelihood of regulatory action in equilibrium. Because the net effect may be quite different across drugs, our empirical analysis will be conducted separately by disease.

The model's validity rests on two testable assumptions. First, higher expenditure on promotion must be associated with a higher rate of adverse event reporting. Second, a higher rate 
of adverse event reporting must be associated with more frequent regulatory action (i.e. $m>0$ ). The focus of the empirical work is to test these assumptions.

\section{Empirical Estimation of Reported Adverse Drug Events}

In this section, we empirically examine one of the main propositions in this paper, whether higher levels of pharmaceutical promotion and advertising lead to a worsening match with patients as reflected by increased reporting of adverse drug reactions (ADRs). We estimate the following:

(7.1) $A D R_{j t}=f\left(\sum_{t=0}^{t-2} A_{j t}, \sum_{t=t-3}^{t-11} A_{j t}, X_{j t}, D_{j}, Y_{t}\right)$,

Where $A D R_{\mathrm{it}}$ is the count of reported adverse drug reactions for drug $j$ at time $t$ (monthly from 2003-2004, and $t=0$ represents the current month). The vector $A$ represents measures of expenditures on advertising and promotion. We consider current quarter expenditures along with the sum of expenditures for the previous three quarters to represent the existing stock of expenditures. Current quarter expenditures are used for two reasons. First, ADRs are reported throughout the month so it is not clear that current month's expenditures are appropriately matched to all observations. In some cases, the previous month is a better match. Second, there may be a time delay between the doctor visit and the filling of a prescription. Including the previous two months allows us to capture promotion and advertising exposure in the near past. For the stock, we do not specify a depreciation rate, rather, we let the coefficients on the stock reflect the product of the marginal effect on reported ADRs and the depreciation rate.

The vector $X_{\mathrm{jt}}$ represents some characteristics of the users of the drug that may influence reporting, $D_{\mathrm{j}}$ are fixed effects for the drug, and $Y_{\mathrm{t}}$ are dummies for each month in the data. The 
drug fixed effects should capture those drug-specific factors related to demand that would occur without promotion or advertising. Some examples might be the results of clinical trials or whether the drug is fundamentally different than its predecessors.

Data on adverse drug reactions come from the U.S. Food and Drug Administration's Adverse Event Reporting System, which was designed for postmarket drug safety surveillance. Manufacturers are required to submit reports of adverse events to the AERS, while reports from doctors, consumers and lawyers are voluntarily contributed. This is the database the FDA uses to inform its regulatory decisions regarding postmarket safety of drugs. In this paper, we consider adverse events associated with prescription drugs used to treat allergies, arthritis, depression, and high cholesterol. These particular drugs are chosen because of their popularity and the high propensity of firms to advertise and promote them. We group drugs by their primary active ingredients because the AERS data do not accurately distinguish between generic and branded versions of a particular molecule. Our list of ingredients is based on the website drugdigest.org. A total of 65 distinct active ingredients are considered, and of these, 11 are for high cholesterol, 10 for allergies, 19 for arthritis, and 25 for depression. Following our conceptual framework, the four conditions represent therapeutic classes that may vary in markup, value, market size, and elasticity of promotion. Because promotion and advertising may have differential effects on the utilization of the drug and resulting ADRs based on the condition for which the drug is prescribed, we estimate the equation separately for the four conditions.

We use monthly counts of adverse events occurring between January 2003 and December 2004 as our dependent variables. We define a "very serious" adverse event based on the FDA definition from the AERS reporting instructions, which includes: death; life-threatening injury; hospitalization; disability or permanent damage; and congenital anomaly / birth defect. The unit 
of observation in the AERS is the event. Multiple drugs can be associated with each event, and we currently treat these as separate observations. ${ }^{12}$

The AERS data suffer from some drawbacks including a lack of denominator data on the number of users, recall bias, poor case documentation and underreporting (IOM pg. 55). We generate denominator data from IMS's National Prescription Audit (NPA) data base. This source has national monthly counts of pharmacy sales of all prescription drugs. From this, we extract the sales (in thousands) of the same ingredients under consideration in the AERS data, and match by linking the drug names to the corresponding ingredient on our list. From the NPA, we also include on the right hand side of the equation a variable with the percent of sales accounted for by generic drugs.

Measurement error in the AERS will be a problem only if the error is correlated with our variables of interest, dollars spent on advertising and promotion. Recall bias and poor case documentation are not likely to be correlated with dollars spent. However, it is possible that reporting patterns for certain drugs are influenced by advertising, for example, if consumers are reminded to report an event based on a television ad. We discuss the possible endogeneity further below.

Olson (2002) notes that adverse event reporting is influenced by the length of time a drug has been on the market with more reports made early in the life cycle of a drug. To account for this possibility, we include in all models indicators for categories of the length of time since approval date as reported in the NPA (0-6 months, 7 months to 2 years, 3-5 years, 6-10 years, and $>10$ years is the omitted category).

\footnotetext{
${ }^{12}$ Vioxx is the only drug in our data to have been withdrawn during our sample period. In the relevant tables below, the observations for Vioxx occurring after the withdrawal date, 9/04, are excluded. Models were tested that exclude all observations for Vioxx and the results are similar to those presented below.
} 
Data on direct to consumer advertising comes from the TMS Media Ad\$pender database (formerly Competitive Media Reports). We use total dollars spent per month on television, magazines, billboards, and Internet advertising for each drug under consideration. ${ }^{13}$ Monthly data on professional promotion comes from IMS’s Integrated Promotion Service (IPS). We consider total dollars spent on contact with physicians and total dollars spent on professional promotion. The latter includes the cost of contact, journal advertising, and the retail value of samples. As with the NPA data, the drug names in these data are linked with the corresponding ingredient on our list. Because of the potential for severe multicollinearity among the two promotion expenditures, each one enters separately into the models. There is much less correlation between promotion and advertising so each model contains a measure of promotion and advertising.

In order to help further explain the variation in adverse events and to account for possible trends or patterns in reporting, we include a number of additional variables in all models. These variables are all generated from IMS Health’s National Disease and Therapeutic Index (NDTI) database. The NDTI is a nationally representative sample of office based physicians in private practice drawn from a universe of all physicians in the United States. All primary specialties involved in direct patient care are included in the sample. Each physician reports demographic and medical information on all patients seen during two consecutive workdays in each calendar quarter. The reports also include “drug appearances:” a mention of a drug during a patient visit, whether as prescriptions, samples, drugs sold or given to the patient from their stock, hospital orders or drug recommendations. Prescriptions make up the majority of appearances so we use the terms prescriptions and appearances interchangeably. Thus the NDTI is a good source for data on the characteristics of users of a particular drug.

\footnotetext{
${ }^{13}$ When a drug is not mentioned in this source, we assume the value of advertising is zero for that month.
} 
From the NDTI, we generate and include the following sets of variables for each drug under consideration: First, we include the share of prescriptions for the drug written for different age groups interacted with gender (ages 0-39, 40-64, 65 and up, with females and males age 0-39 as the omitted reference group). Second, we include the share of prescriptions paid for by government insurance, and third, the share prescriptions written for smokers. Fourth, we have shares for Asian and black race and Hispanic ethnicity. Finally, we have shares of prescriptions written for patients with prehypertension, stage 1 hypertension, and stage 2 hypertension. All of these variables are calculated per year to reduce sampling variability.

Given that cases of adverse events are counts and have many zeros, we use a count model to estimate the models. Specifically we use a Fixed Effects Poisson (FEP) method (Wooldridge, 2002; Cameron and Trivedi, 1998). This estimator is a quasi-maximum likelihood estimator that includes fixed effects to account for unobserved heterogeneity. Estimates are consistent regardless of whether the counts actually have a Poisson distribution (Wooldridge, 2002). To permit overdispersion, a common feature of count data that is not accommodated by the Poisson maximum likelihood estimator, standard errors are adjusted for heterocedasticity of unknown form (Cameron and Trivedi, 2005). Each model includes the log of the number of prescriptions for the drug in each month as a right hand side variable to normalize for exposure in the population. The coefficient on prescriptions is constrained to equal one. ${ }^{14}$

\section{Results of Reported Adverse Drug Events}

Table 1 show the means and standard deviations of all the variables based on the sample of drugs for each of the four conditions (arthritis, depression, high cholesterol, and allergies). It

\footnotetext{
${ }^{14}$ Alternative models were tested using a negative binomial regression with fixed effects. The results are extremely similar to those presented in the tables below.
} 
is clear from this table that reported very serious adverse drug events are rare. The average monthly count ranges from a low of 13.87 for allergy drugs, to a high of 48.89 for cholesterol drugs. However, the rates of reported adverse events, which account for the size of the population of users, are very similar for allergy and cholesterol drugs at 0.02 and 0.03 per 1,000 users, respectively. Arthritis and depression drugs have higher reported rates at 0.09 and 0.08 per 1,000 users, respectively.

The table also shows that these pharmaceuticals are heavily promoted. Average current quarterly real expenditures on profession promotion and direct-to-consumer advertising combined total \$11 million for arthritis drugs, \$12.41 million for depression drugs, \$26.8 million for cholesterol lowering drugs and $\$ 26.20$ million for allergy drugs. Note that the bulk of this total comes from professional promotion which includes not only the cost of contact with the physician but also includes the retail value of samples and the cost of professional journal advertisements.

Tables 2 and 3 show results from the FEP estimation of reported adverse drug reactions for arthritis and depression (Table 2) and cholesterol and allergies (Table 3). Each column in the tables represents a separate regression. Within each condition, the first column includes the total sum of dollars spent on professional promotion and DTCA. The second column separates total professional promotion from DTCA and includes both sources of expenditures in the models. The third column replaces total promotion dollars with the cost of contact, but also include total DTCA spending.

The coefficients in the FEP can be interpreted as semi-elasticities, that is, the percentage change in the ADR count from a one unit change in the independent variable. When expenditures on advertising or promotion are considered, we want to know the total effect of this 
spending over all time periods. The relevant effect therefore is the sum of the current and past expenditures, with consideration that the coefficient on past expenditures includes an unspecified depreciation rate.

Consider first the results for arthritis in Table 2. The results show conflicting evidence for the total sum of expenditures in column 1, however, these results seem to be driven by differential effects between DTCA and promotion activities. Column 2 shows a negative and insignificant effect of current professional promotion along with a positive and statistically significant coefficient on the past stock. Given the insignificance of the current value, we consider the combined effect to be positive based on the stock's coefficient. Note that magnitude of the effect of the stock will be smaller than what is shown depending on the size of the depreciation rate. Expenditures on contact with physicians shows a similar positive effect on reported adverse drug events, with a one standard deviation increase in detailing expenditures raising ADR reporting by approximately 65 percent. Here, the current and past expenditures are both positive, and the stock is significant at the 5 percent level. Expenditures on direct-toconsumer advertising for arthritis drugs are also positively related to reported adverse drug events, with a one standard deviation increase in DTCA raising ADR reporting by approximately 20 percent. Again, the current and past expenditure are positive and the stock is significant. These results supply support for our assertion that advertising and promotion can worsen the match between the drug and patients.

Depression drugs are also considered in Table 2. Here, professional promotion, measured either as the total expenditure or as the cost of contact with physicians, has no statistical relationship with reported adverse events. By contrast, the coefficients on the stock of DTCA are positive and statistically significant, with a one standard deviation increase in DTCA 
raising ADR reporting by approximately 5 percent. These results imply that promotion to professionals has no harmful effects on patients, while DTCA may be detrimental.

The results in Table 3 are much different for cholesterol lowering drugs and allergies. With the exception of one coefficient on the stock of DTCA in the third allergy model, no other coefficient in any of these models is positive and statistically significant, suggesting there is no harmful effect of promotion and advertising for these types of drugs. For cholesterol drugs, higher expenditures on professional promotion may be helpful in that these expenditures are negatively associated with reported adverse events, with a one standard deviation increase in detailing expenditure lowering ADR reporting by approximately 25 percent. The same can be said for allergy medications, where the current quarter expenditures on total promotion and cost of contact are negative and statistically significant.

We are concerned with the potential endogeneity of pharmaceutical advertising and promotion expenditures in the equation for reported ADRs. Endogeneity that stems from any unobserved, drug-specific characteristics should be accounted for by the drug fixed effects. However, it is possible that reports of adverse drug events may affect the firm's decisions regarding the levels of professional promotion and DTCA. The first check we conduct for this type of endogeneity bias re-estimates the models presented in Tables 2 and 3 excluding the current month's expenditure values. That is, we use the first two lags of expenditures (months t1 and $t-2$ ) along with the stock variables (months $t-3$ through $t-11$ ). Hence, the model reflects the effects of all past values of expenditures on the current month reported ADRs. Logically, reverse causality should not be a problem. Indeed, results from this estimation are very similar in sign and statistical significance (available upon request). 
We use instrumental variables for our second check for endogeneity. We instrument for the current quarter's expenditures on professional promotion and cost of contact using expenditures on these activities for all drugs manufactured by the same company. For example, suppose a drug in our sample is made by only one manufacturer. The instrument is total expenditures on profession promotion for that manufacturer on all drugs it produces, excluding the drug under consideration. If there are multiple companies that produce a drug in our sample, then the expenditures by these manufacturers are all considered as possible instruments. The idea here is that certain firms may, as a business practice, tend to promote more than other firms. This would ideally predict current expenditures for the drugs in our sample, but be unrelated to reported adverse events for that drug.

Unfortunately, the instruments do not work well for all the conditions under consideration in our sample. They work best for cholesterol lowering drugs and depression drugs. The IV results for these models show no evidence of endogeneity. For example, the instrument in the first stage regression predicting total professional promotion among cholesterol lowering drugs are jointly significant with a F-statistic of 9.90. The OLS and IV estimates of current professional promotion are both negative and significant, and the appropriate test does not reject the consistency of the OLS coefficient. ${ }^{15}$ In other cases where the first stage Fstatistics is statistically significant and above 5, the consistency of OLS cannot be rejected and the OLS and IV coefficients are similar. Given this evidence, and that presented above, we are confident that endogeneity is not a problem.

\footnotetext{
${ }^{15}$ The IV technique is described by Wooldridge (2002) for count models with endogenous right hand side variables. This is a two-step procedure that runs a first stage model via OLS. The residuals from the first stage are then predicted and included as an additional covariate in the second stage model, which is estimated by Poisson regression. Standard errors are adjusted to be robust to heteroscedasticity. The resulting estimates are consistent. The endogeneity of expenditures is tested by examining the t-statistic on the first stage residuals in the second equation.
} 


\section{Reported Adverse Drug Events and FDA Regulation}

In this section we examine empirically the extent to which the FDA appears to react to signals from the AERS to make regulatory decisions $\left(R_{j, t}\right)$. Equation (7.2) shows this relationship, with consideration to the drug characteristics $\left(X_{j t}\right)$ and regulatory environment at a particular time $\left(Y_{t}\right)$ :

$$
R_{j t}=f\left(A D R_{j t}, X_{j t}, Y_{t}\right) .
$$

Below, we estimate alternative specifications of equation (7.2) that examine the effects of monthly, quarterly, and yearly adverse drug events reports on regulator action.

Information on safety-based reactions $(R)$ comes from the FDA's MedWatch summaries. MedWatch lists monthly actions pertaining to five safety labeling changes: boxed warnings, contraindications, warnings, precautions, and adverse reactions. From this information, we generate two measures of regulatory actions. The first is a drug-specific dichotomous indicator for the month in which the FDA required the manufacturers of that drug to change the label to include any of the above listed changes. The indicator reverts back to zero in any month for which there is no new labeling change required. Logit regressions are used to analyze the effects of reported ADRs on the probability of a new labeling change. However, since it is possible that reported ADRs will fall after a labeling change and generate a reverse causality problem, we also estimate a discrete time hazard model. The estimation of this model will tell the effects of reported ADRs on the probability of the first labeling change occurring. The disadvantage to this model is that only the first change is considered, although it is not a severe concern since few drugs experience multiple labeling changes, with the bulk of these changes occurring in consecutive months. 
Labeling changes are relatively rare events and occur in only 4 percent of the drug/month observations. Just over half of the drugs in the sample experience a labeling change at some point, and these changes are concentrated most heavily among the allergy drugs (25 percent of the labeling changes) and the antidepressants (47 percent of the labeling changes). Cholesterol drugs and arthritis drugs account for 11 percent and 17 percent, respectively. Because of these characteristics, there is not enough variation in the labeling changes to estimate the logit models for each condition separately, or to include drug fixed effects. We instead run a pooled model allowing for condition-specific slopes for reported ADRs, along with the time-varying drug and user characteristics and year/month indicators.

The first three columns of Table 4 show that reported ADRs are positive and statistically significantly associated with the probability of a labeling change for arthritis and depression drugs. In general, the association holds whether the current month, current quarter, or current year is the relevant time span for reported ADRs. The association is also generally positive, but not statistically significant, for cholesterol and allergy drugs. The effects are substantial considering the probability of a labeling change is 0.04 . Consider a marginal effect of 0.0001 for arthritis or depression drugs. This means that every 100 additional adverse drug reports increases the probability of a labeling change by one percentage point, a fourth of the baseline rate.

The second three columns of Table 4 show the results of the discrete time hazard model. We find that increases in reported ADRs are associated with an increase in the probability of the first incidence of a labeling change. Here, statistical significance varies somewhat depending on the timing of the ADRs under consideration, however, all coefficients are positive, yet 
consistently insignificant only for the cholesterol drugs. The magnitudes of the effects are also similar to that of the first three models.

\section{Conclusions}

The growth of pharmaceutical promotion, particularly direct-to-consumer advertising, along with recent drug withdrawals and other regulatory interventions calls for an understanding of the basic relationship between the promotion of a drug and the benefit-risk profile of its users. In this paper we have provided a theoretical framework for the behavior of a pharmaceutical firm under regulation by the FDA, and we have tested aspects of this model using an innovative combination of data on promotion, regulation, and adverse reactions. The model shows how product and market characteristics such as the elasticity of promotion would lead to different levels of promotion and regulatory oversight, and how consumer welfare is affected by these changes.

The empirical results confirm the basic assumptions and predictions of our model. We find that promotion increases the rate of reported adverse drug reactions for cholesterol and depression drugs, and the FDA responds to high numbers of reported adverse drug reactions with a greater probability of regulatory action. The results are different for drugs treating different conditions, and we interpret this as primarily a consequence of differences in the ability of physicians to function as gatekeepers. High cholesterol is detected with a simple diagnostic test, and this test is widely used to determine whether to prescribe a drug. Therefore, for this condition, any negative effect of promotion on the average match quality would be limited. Similarly for allergies, diagnostic tests are relatively simple to perform and widely used. 
It may not be surprising to see the effect of promotion come through the stock rather than current expenditures. Our "current” time period is defined as three months, and there are several steps that must occur between the promotion of a drug and an adverse reaction. First, patients and/or physicians must receive the promotion, then interact with one another such that the drug is prescribed. The patient must then fill the prescription and take the drug, and finally the unanticipated toxicity must accumulate to the point that it causes an adverse reaction. Depending on an individual's circumstance, this process could be swift or take more than a few months.

Our analysis is limited by the fact that we do not model the strategic interactions among firms producing the same drug or drugs within the same class. However, given the complexity of our monopoly model, incorporating competition among firms seems prohibitive, and it is not of primary importance for this topic. Similarly, our model is static and ignores the possibility that physicians could learn to prescribe more appropriately over time, but this too seems overly complicated for our purposes. The empirical work accounts for these issues by including the share of generics and the age of the drug as variables, and our predictions hold with these controls in place. A limitation of the empirical results is that we use a simple form for the effect of promotion on ADRs because we do not know the functional relationship between promotion and demand. For example, it is possible that promotion at the time of a drug's introduction operates differently than later promotion.

An important conclusion from this analysis is that the relationship between promotion and ADRs depends greatly on the condition. Our estimates show detailing reduces the adverse event rate for high cholesterol and allergy drugs, while DTCA increases the rate for arthritis and depression, as does detailing for arthritis. Conceptually, drug promotion can be beneficial or detrimental, and we believe the net effect depends critically on the role of physicians as 
mediators between promotion and use. The effect of promotion and advertising in improving communication between patients and physicians may be welfare increasing if physicians can identify who is the best match for treatment. This is facilitated in the case of cholesterol and allergy medications by the existence of simple diagnostic tests. Public policy on pharmaceutical advertising and promotion should take this into account. For conditions where physicians can perform their role as mediators there is less need for concern about inappropriate use due to promotion, but for conditions where the diagnosis or risks are hard to assess there may be a need for greater oversight and investment in postmarketing surveillance. 


\section{References:}

Almasi EA, Stafford RS, Kravitz RL, Mansfi eld PR (2006) What are the public health effects of direct-to-consumer drug advertising? PLoS Med 3(3): e145.

Ashraf, Nava, James Berry and Jesse M. Shapiro "Can Higher Prices Stimulate Product Use? Evidence from a Field Experiment in Zambia” Poverty Action Lab Paper No. 41, January 2007

Bell RA, Wilkes MS, Kravitz RL. "The educational value of consumer targeted prescription drug print advertising.” Journal of Family Practice, 2000;49:1092-8.

Berndt, Ernst R., “The United States' Experience with Direct-to-Consumer Advertising of Prescription Drugs: What Have We Learned?” In Frank A. Sloan and Chee-Ruey Hsieh, eds., Promoting and Coping with Pharmaceutical Innovation: An International Perspective, Cambridge University Press, 2006.

Berndt, Ernst R.; Gottschalk, Adrian H. B.; Philipson, Tomas J.; Strobeck, Matthew W. "Industry funding of the FDA: effects of PDUFA on approval times and withdrawal rates." Nature Reviews Drug Discovery, July 2005, Vol. 4 Issue 7, p545-554,

Bradford, W. David, Andrew N. Kleit, Paul J. Nietert, Terrence Steyer, Thomas McIlwain, and Steven Ornstein. "How Direct-To-Consumer Television Advertising For Osteoarthritis Drugs Affects Physicians’ Prescribing Behavior.” Health Affairs 25, no. 5 (2006): 1371-1377.

Brichacek, Andra and L.J. Sellers. "Flexing Their Budgets: Big Pharma Spend Trends." Pharmaceutical Executive, September 1, 2001.

Brick, Ivan E. and Harsharanjeet S. Jagpal "Monopoly Price-Advertising Decision-Making under Uncertainty” Journal of Industrial Economics, Vol. 29, No. 3 (Mar., 1981), pp. 279-285.

Buckley, Joan. "The Need to Develop Responsible Marketing Practice in the Pharmaceutical Sector.” Problems and Perspectives in Management, 4(2004), 92-103.

Calfee, John E., Clifford Winston, and Randolph Stempski. "Direct-to-Consumer Advertising and the Demand for Cholesterol-Reducing Drugs" The Journal of Law and Economics, volume 45 (2002), pages 673-690

Chao BA (2005) Evaluating the educational content of direct-to-consumer fulfillment materials. Am J Health Syst Pharm 62: 620-625.

Dehez, Pierre and Alex Jacquemin “A Note on Advertising Policy under Uncertainty and Dynamic Conditions” Journal of Industrial Economics, Vol. 24, No. 1 (Sep., 1975), pp. 73-78.

Donohue, Julie M., Ernst R. Berndt, Meredith Rosenthal, Arnold M. Epstein and Richard G. Frank [2004], "Effects of Pharmaceutical Promotion on Adherence to Guideline Treatment of Depression”, Medical Care, Vol. 42, No. 12, December, pp. 1176-1185. 
Dorfman, Robert and Peter O. Steiner "Optimal Advertising and Optimal Quality" American Economic Review, Vol. 44, No. 5 (Dec., 1954), pp. 826-836.

GAO. Prescription Drugs FDA Oversight of Direct-to-Consumer Advertising Has Limitations. GAO-03-177. Washington, DC: GAO, 2002.

Horowitz, Ira “A Note on Advertising and Uncertainty” Journal of Industrial Economics, Vol. 18, No. 2 (Apr., 1970), pp. 151-160.

Iizuka, Toshiaki and Ginger Zhe Jin. "The Effect of Prescription Drug Advertising on Doctor Visits.” Journal of Economics \& Management Strategy, 14(3), Fall 2005, 701-727.

Institute of Medicine. The Future Of Drug Safety: Promoting And Protecting The Health Of The Public. Alina Baciu, Kathleen Stratton, Sheila P. Burke, Editors. The National Academies Press: Washington, DC. 2007.

Kravitz, Richard I., Ronald M. Epstein, Mitchell D. Feldman, Carol E. Franz, Rahman Azari, Michael S. Wilkes, Ladson Hinton and Peter Franks [2005], "Influence of Patients' Requests for Direct-to-Consumer Advertised Antidepressants: A Randomized Controlled Trial”, Journal of the American Medical Association, Vol. 293, No. 16, April 27, pp. 1995-2002.

Lam, Michael D. “A \$20 Billion Bill and Plenty of Change.” Pharmaceutical Executive, September 1, 2004.

Masson A. and P.H. Rubin, "Matching Prescription Drugs and Consumers: The Benefits of Direct Advertising," New England Journal of Medicine 313, no. 8 (1985): 513-515.

Mintzes, Barbara, Morris L Barer, Richard L Kravitz, Arminée Kazanjian, Ken Bassett, Joel Lexchin, Robert G Evans, Richard Pan, Stephen A Marion, "Influence of direct to consumer pharmaceutical advertising and patients' requests on prescribing decisions: two site cross sectional survey” British Medical Journal 2002;324:278-279.

Narayanan, Sridhar, Ramarao Desiraju, and Pradeep K. Chintagunta (2004), "Return on Investment Implications for Pharmaceutical Promotional Expenditures: The Role of MarketingMix Interactions,” Journal of Marketing, 68 (October), 90-105.

Olson, Mary K. “Are Novel Drugs More Risky for Patients Than Less Novel Drugs?” Journal of Health Economics, November 2004, v. 23, iss. 6, pp. 1135-58

Olson, Mary K., "Pharmaceutical Policy Change and the Safety of New Drugs.” Journal of Law and Economics, Part 2 October 2002, v. 45, iss. 2, pp. 615-42

Rawson, Nigel SB and Kenneth I Kaitin. "Canadian and US Drug Approval Times and Safety Considerations.” The Annals of Pharmacotherapy. October 2003;37:1403-8.

Rizzo, John. "Advertising and Competition in the Ethical Pharmaceutical Industry: The Case of Antihypertensive Drugs.” Journal of Law and Economics. 42(1) April 1999, 89-116. 
Rudholm, Niklas, “Approval Times and the Safety of New Pharmaceuticals.” European Journal of Health Economics, December 2004, v. 5, iss. 4, pp. 345-50

Spence MM, Teleki SS, Cheetham TC, Schweitzer SO, Millares M (2005) Direct-to-consumer advertising of COX-2 inhibitors: Effect on appropriateness of prescribing. Medical Care Research and Review 62: 544-559.

Taubes, Gary. “Do We Really Know What Makes Us Healthy.” New York Times Magazine, September 16, 2007.

U.S. Food and Drug Administration. CDER 2005: Report to the Nation: Improving Public Health Through Human Drugs. Rockville, Maryland. 2005.

West, Mary. “Spend Trends 2007: Hang 10, DTC Hits Its first Decade” Pharmaceutical Executive, May 1, 2007.

[http://www.pharmexec.com/pharmexec/article/articleDetail.jsp?id=423215\&searchString=trend s\%20in\%20DTC. Accessed November 13, 2007.]

Windmeijer, Frank, Eric de Laat, Rudy Douven and Esther Mot. "Pharmaceutical promotion and GP prescription behaviour.” Health Economics, 15(1), January 2006, 5-18.

Wooldridge, Jeffrey M., Econometric Analysis of Cross Section and Panel Data, Cambridge, MA: MIT Press, 2002.

Wosinska, Marta. “Direct-to-Consumer Advertising and Drug Therapy Compliance”, Journal of Marketing Research. 42(3), August 2005, 323-332. 
Figure 1: The safety - benefit space for patients

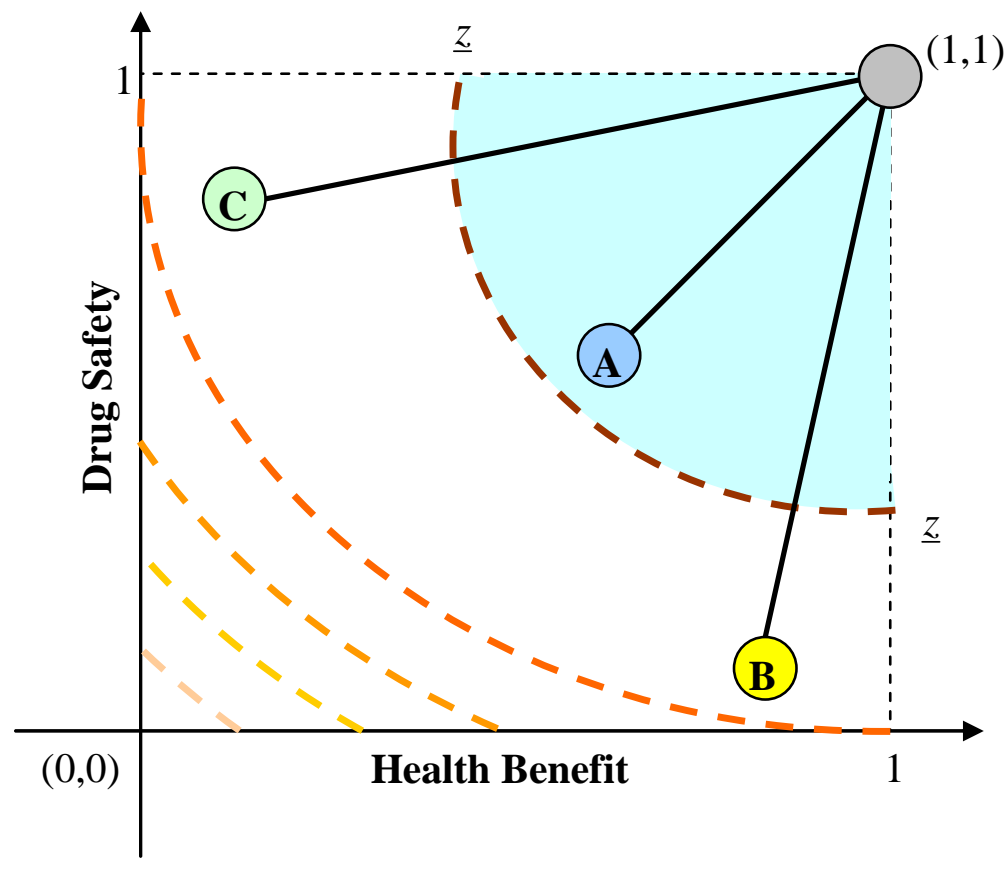


Figure 2: Optimal level of promotion expenditures

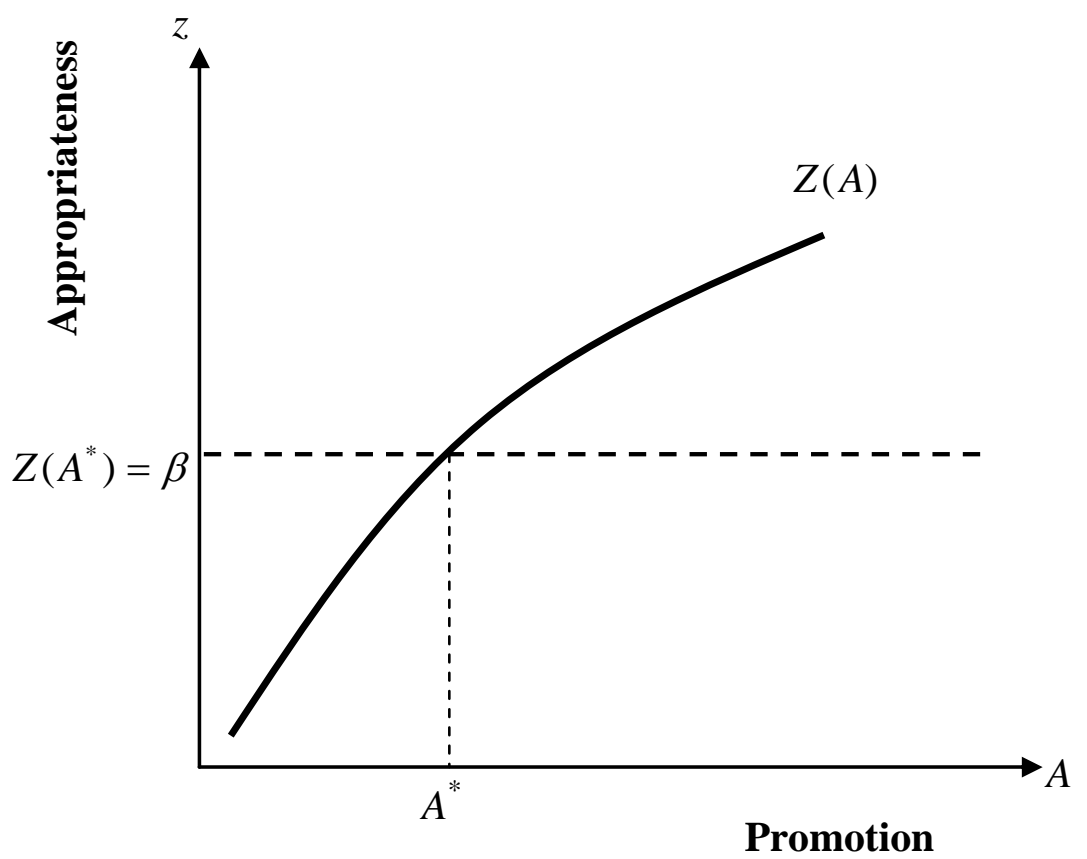


Table 1

Means, Standard Deviations by Condition

\begin{tabular}{|c|c|c|c|c|c|c|c|c|}
\hline \multirow[t]{2}{*}{ Variable } & \multicolumn{2}{|c|}{$\begin{array}{l}\text { Arthritis } \\
(\mathrm{n}=429)\end{array}$} & \multicolumn{2}{|c|}{$\begin{array}{c}\text { Depression } \\
(\mathrm{n}=540)\end{array}$} & \multicolumn{2}{|c|}{$\begin{array}{c}\text { High Cholesterol } \\
(n=247)\end{array}$} & \multicolumn{2}{|c|}{$\begin{array}{l}\text { Allergies } \\
(\mathrm{n}=240)\end{array}$} \\
\hline & Mean & S.D & Mean & S.D & Mean & S.D & Mean & S.D \\
\hline Very Serious ADR & 37.91 & 82.08 & 33.90 & 37.21 & 49.89 & 71.57 & 13.87 & 11.54 \\
\hline Total prescriptions & 363.4 & 524.2 & 1086.8 & 1197.5 & 2312.8 & 3405.4 & 934.6 & 735.3 \\
\hline Very Serious ADR rate & 0.09 & 0.10 & 0.08 & 0.17 & 0.02 & 0.02 & 0.03 & 0.04 \\
\hline $\begin{array}{l}\text { Current quarter total promotion and DTCA } \\
\quad(\text { real } \$ 1,000,000)\end{array}$ & 11.00 & 23.23 & 12.41 & 22.94 & 26.80 & 40.56 & 26.20 & 20.14 \\
\hline $\begin{array}{l}\text { Stock total promotion and DTCA } \\
\quad(\text { real } \$ 1,000,000)\end{array}$ & 33.80 & 71.92 & 36.38 & 64.27 & 75.12 & 111.87 & 79.07 & 58.61 \\
\hline $\begin{array}{l}\text { Current quarter professional promotion } \\
\quad \text { (real } \$ 1,000,000)\end{array}$ & 9.65 & 20.09 & 10.82 & 19.94 & 22.84 & 34.57 & 20.57 & 13.69 \\
\hline $\begin{array}{l}\text { Stock of professional promotion } \\
\quad(\text { real } \$ 1,000,000)\end{array}$ & 30.21 & 63.58 & 31.83 & 55.39 & 64.70 & 96.00 & 61.12 & 40.49 \\
\hline $\begin{array}{l}\text { Current quarter cost of contact } \\
\quad(\text { real } \$ 1,000,000)\end{array}$ & 3.02 & 6.17 & 2.87 & 5.39 & 4.47 & 4.96 & 6.68 & 4.85 \\
\hline $\begin{array}{l}\text { Stock of cost of contact } \\
\quad(\text { real } \$ 1,000,000)\end{array}$ & 9.42 & 19.43 & 8.65 & 15.20 & 13.53 & 14.90 & 20.91 & 15.17 \\
\hline $\begin{array}{l}\text { Current quarter DTCA } \\
\quad(\text { real } \$ 1,000,000)\end{array}$ & 1.35 & 4.05 & 1.59 & 4.49 & 3.96 & 7.84 & 5.62 & 8.45 \\
\hline $\begin{array}{l}\text { Stock of DTCA } \\
\quad(\text { real } \$ 1,000,000)\end{array}$ & 3.58 & 10.46 & 4.55 & 12.30 & 10.42 & 17.18 & 17.95 & 21.69 \\
\hline Percent generics & 0.71 & 0.41 & 0.57 & 0.45 & 0.28 & 0.44 & 0.17 & 0.34 \\
\hline Percent of drug prescribed to smokers & 0.21 & 0.13 & 0.21 & 0.10 & 0.14 & 0.05 & 0.11 & 0.02 \\
\hline Percent of drug prescribed to prehypertension & 0.48 & 0.15 & 0.51 & 0.19 & 0.51 & 0.05 & 0.47 & 0.05 \\
\hline Percent of drug prescribed to stage 1 hypertension & 0.26 & 0.16 & 0.16 & 0.10 & 0.25 & 0.07 & 0.16 & 0.06 \\
\hline Percent of drug prescribed to stage 2 hypertension & 0.08 & 0.12 & 0.05 & 0.07 & 0.07 & 0.06 & 0.04 & 0.03 \\
\hline Percent of drug $\mathrm{w} /$ government insured users & 0.27 & 0.11 & 0.32 & 0.14 & 0.40 & 0.09 & 0.24 & 0.10 \\
\hline Percent of drug prescribed to Asians & 0.02 & 0.03 & 0.01 & 0.02 & 0.04 & 0.02 & 0.04 & 0.01 \\
\hline Percent of drug prescribed to blacks & 0.10 & 0.05 & 0.04 & 0.03 & 0.08 & 0.05 & 0.10 & 0.02 \\
\hline Percent of drug prescribed to Hispanics & 0.07 & 0.05 & 0.03 & 0.02 & 0.05 & 0.02 & 0.07 & 0.02 \\
\hline Drug approval date 5 years -10 years & 0.04 & 0.20 & 0.19 & 0.39 & 0.24 & 0.43 & 0.57 & 0.50 \\
\hline Drug approval date 2 years -5 years & 0.15 & 0.36 & 0.02 & 0.14 & 0.11 & 0.31 & 0.05 & 0.23 \\
\hline Drug approval date 7 months -2 years & 0.03 & 0.17 & 0.03 & 0.18 & 0.03 & 0.17 & 0.05 & 0.21 \\
\hline Drug approval date $<=6$ months & 0.00 & 0.00 & 0.002 & 0.04 & 0.00 & 0.00 & 0.00 & 0.00 \\
\hline Percent of drug prescribed to females ages $40-64$ & 0.25 & 0.10 & 0.36 & 0.14 & 0.19 & 0.03 & 0.20 & 0.04 \\
\hline Percent of drug prescribed to females ages $65+$ & 0.14 & 0.11 & 0.11 & 0.07 & 0.25 & 0.08 & 0.08 & 0.03 \\
\hline Percent of drug prescribed to males ages $40-64$ & 0.20 & 0.11 & 0.16 & 0.08 & 0.24 & 0.09 & 0.13 & 0.02 \\
\hline Percent of drug prescribed to males ages $65+$ & 0.09 & 0.05 & 0.05 & 0.06 & 0.21 & 0.05 & 0.08 & 0.07 \\
\hline
\end{tabular}


Table 2

Effects of Promotion and Direct to Consumer Advertising on Adverse Drug Events Reports for Arthritis and Depression

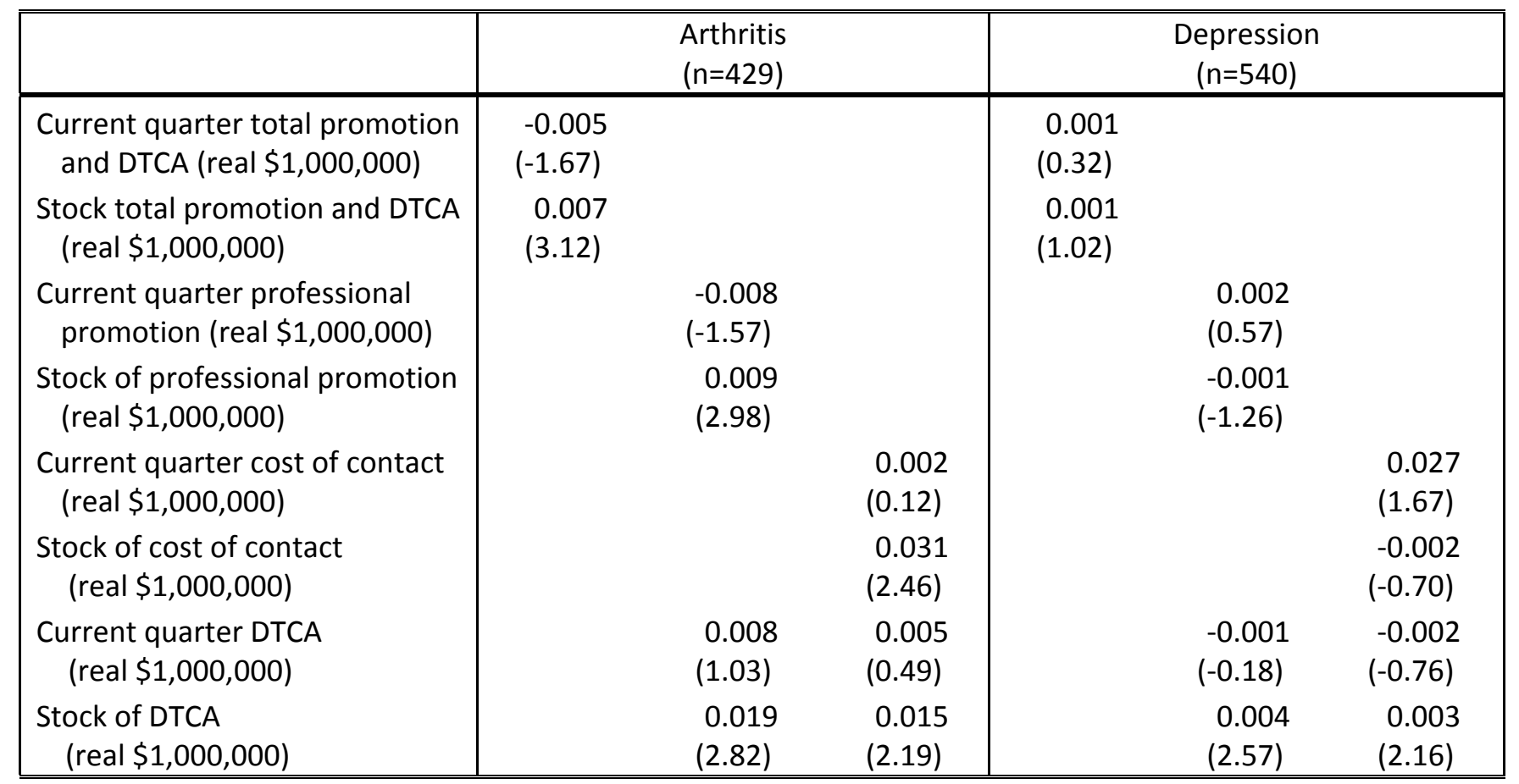

Notes: T-statistics in parentheses. Each column is a separate regression. Coefficients represent the percent change in the outcome resulting from one unit change in the independent variable. All models include share of prescriptions written for: females ages 40-64; males ages 40-64; females ages 65 and up; males ages 65 and up; Asian and black races and Hispanic ethnicity; smokers; people with government insurance; prehypertension, stage 1 hypertension, and stage 2 hypertension. Models also include share of generics, indicators for drug approval dates, year/month indicators and drug fixed effects. The log of total prescriptions is included on the right hand side with the coefficient constrained to one. 
Table 3

Effects of Promotion and Direct to Consumer Advertising on Adverse Drug Events Reports for High Cholesterol and Allergies

\begin{tabular}{|c|c|c|c|c|c|}
\hline & \multicolumn{2}{|c|}{$\begin{array}{l}\text { High Cholesterol } \\
(n=247)\end{array}$} & \multicolumn{3}{|c|}{$\begin{array}{l}\text { Allergies } \\
(n=240)\end{array}$} \\
\hline $\begin{array}{l}\text { Current quarter total promotion } \\
\text { and DTCA (real } \$ 1,000,000 \text { ) }\end{array}$ & $\begin{array}{l}-0.002 \\
(-1.65)\end{array}$ & & $\begin{array}{l}-0.006 \\
(-1.46)\end{array}$ & & \\
\hline $\begin{array}{l}\text { Stock total promotion and DTCA } \\
\quad(\text { real } \$ 1,000,000)\end{array}$ & $\begin{array}{l}0.0001 \\
(0.12)\end{array}$ & & $\begin{array}{c}0.002 \\
(0.64)\end{array}$ & & \\
\hline $\begin{array}{l}\text { Current quarter professional } \\
\text { promotion (real } \$ 1,000,000 \text { ) }\end{array}$ & $\begin{array}{l}-0.003 \\
(-2.14)\end{array}$ & & & $\begin{array}{l}-0.020 \\
(-3.43)\end{array}$ & \\
\hline $\begin{array}{l}\text { Stock of professional promotion } \\
\quad \text { (real } \$ 1,000,000)\end{array}$ & $\begin{array}{l}0.0004 \\
(0.48)\end{array}$ & & & $\begin{array}{l}0.003 \\
(0.90)\end{array}$ & \\
\hline $\begin{array}{l}\text { Current quarter cost of contact } \\
\quad(\text { real } \$ 1,000,000)\end{array}$ & & $\begin{array}{l}-0.024 \\
(-1.72)\end{array}$ & & & $\begin{array}{l}-0.051 \\
(-3.42)\end{array}$ \\
\hline $\begin{array}{l}\text { Stock of cost of contact } \\
\quad(\text { real } \$ 1,000,000)\end{array}$ & & $\begin{array}{l}-0.015 \\
(-2.25)\end{array}$ & & & $\begin{array}{r}0.008 \\
(1.04)\end{array}$ \\
\hline $\begin{array}{l}\text { Current quarter DTCA } \\
\quad(\text { real } \$ 1,000,000)\end{array}$ & $\begin{array}{c}0.001 \\
(0.21)\end{array}$ & $\begin{array}{c}0.002 \\
(0.58)\end{array}$ & & $\begin{array}{c}0.002 \\
(0.47)\end{array}$ & $\begin{array}{c}0.004 \\
(0.86)\end{array}$ \\
\hline $\begin{array}{l}\text { Stock of DTCA } \\
(\text { real } \$ 1,000,000)\end{array}$ & $\begin{array}{l}-0.0004 \\
(-0.21)\end{array}$ & $\begin{array}{c}-0.001 \\
(-0.34)\end{array}$ & & $\begin{array}{c}0.004 \\
(1.41)\end{array}$ & $\begin{array}{r}0.005 \\
(1.65)\end{array}$ \\
\hline
\end{tabular}

Notes: T-statistics in parentheses. Each column is a separate regression. Coefficients represent the percent change in the outcome resulting from one unit change in the independent variable. All models include share of prescriptions written for: females ages 40-64; males ages 40-64; females ages 65 and up; males ages 65 and up; Asian and black races and Hispanic ethnicity; smokers; people with government insurance; prehypertension, stage 1 hypertension, and stage 2 hypertension. Models also include share of generics, indicators for drug approval dates, year/month indicators and drug fixed effects. The log of total prescriptions is included on the right hand side with the coefficient constrained to one. 
Table 4

Effects of Reported Adverse Events on Probability of FDA Action

\begin{tabular}{|c|c|c|c|c|c|c|}
\hline & \multicolumn{3}{|c|}{ Probability of any labeling change } & \multicolumn{3}{|c|}{$\begin{array}{c}\text { Hazard models: Probability of first } \\
\text { labeling change }\end{array}$} \\
\hline & $\begin{array}{c}\text { Current } \\
\text { month's } \\
\text { reports }\end{array}$ & $\begin{array}{l}\text { Current } \\
\text { quarter's } \\
\text { reports }\end{array}$ & $\begin{array}{l}\text { Current } \\
\text { year's } \\
\text { reports }\end{array}$ & $\begin{array}{l}\text { Current } \\
\text { month's } \\
\text { reports }\end{array}$ & $\begin{array}{c}\text { Current } \\
\text { quarter's } \\
\text { reports }\end{array}$ & $\begin{array}{l}\text { Current } \\
\text { year's } \\
\text { reports }\end{array}$ \\
\hline Reported adverse events: arthritis drugs & $\begin{array}{l}0.004 \\
{[0.0001]} \\
(2.03)\end{array}$ & $\begin{array}{l}0.002 \\
{[0.0001]} \\
(2.65)\end{array}$ & $\begin{array}{l}0.001 \\
{[0.00002]} \\
(2.71)\end{array}$ & $\begin{array}{l}0.004 \\
{[0.0001]} \\
(1.24)\end{array}$ & $\begin{array}{l}0.003 \\
{[0.0001]} \\
(1.72)\end{array}$ & $\begin{array}{l}0.002 \\
{[0.00005]} \\
(2.35)\end{array}$ \\
\hline Reported adverse events: depression drugs & $\begin{array}{l}0.011 \\
{[0.0003]} \\
(1.82)\end{array}$ & $\begin{array}{l}0.004 \\
{[0.0001]} \\
(1.57)\end{array}$ & $\begin{array}{l}0.002 \\
{[0.00005]} \\
(2.70)\end{array}$ & $\begin{array}{l}0.014 \\
{[0.0003]} \\
(1.81)\end{array}$ & $\begin{array}{l}0.004 \\
{[0.0001]} \\
(1.05)\end{array}$ & $\begin{array}{l}0.002 \\
{[0.00004]} \\
(1.88)\end{array}$ \\
\hline Reported adverse events: cholesterol drugs & $\begin{array}{l}0.006 \\
{[0.0002]} \\
(1.33)\end{array}$ & $\begin{array}{l}0.003 \\
{[0.0001]} \\
(1.50)\end{array}$ & $\begin{array}{l}0.001 \\
{[0.00001]} \\
(1.31)\end{array}$ & $\begin{array}{l}0.005 \\
{[0.0001]} \\
(1.06)\end{array}$ & $\begin{array}{l}0.003 \\
{[0.0001]} \\
(1.40)\end{array}$ & $\begin{array}{l}0.001 \\
{[0.00002]} \\
(1.29)\end{array}$ \\
\hline Reported adverse events: allergy drugs & $\begin{array}{l}0.023 \\
{[0.0006]} \\
(1.08)\end{array}$ & $\begin{array}{l}0.006 \\
{[0.0001]} \\
(0.67)\end{array}$ & $\begin{array}{c}-0.0001 \\
{[-0.000001]} \\
(-0.02)\end{array}$ & $\begin{array}{l}0.049 \\
{[0.0011]} \\
(1.81)\end{array}$ & $\begin{array}{l}0.027 \\
{[0.0005]} \\
(2.04)\end{array}$ & $\begin{array}{l}0.0208 \\
{[0.0004]} \\
(2.18)\end{array}$ \\
\hline $\mathrm{N}$ & 1321 & 1319 & 1303 & 747 & 746 & 733 \\
\hline
\end{tabular}

Notes: Logit coefficients, t-statistics in parentheses, marginal effects in brackets. Other variables include share of prescriptions written for: females ages 40-64; males ages 40-64; females ages 65 and up; males ages 65 and up; Asian and black races and Hispanic ethnicity; smokers; people with government insurance; prehypertension, stage 1 hypertension, and stage 2 hypertension. Models also include indicators for drug approval dates and year/month indicators. 


\section{Appendix A: Implications of Joint, Uniform Distribution of $(b, s)$.}

Suppose that individuals are distributed uniformly throughout the unit square in Figure 1.1. This means both potential benefit and risk are uniform over $[0,1]$ and are uncorrelated. $^{16}$ Hence $f_{S}(s)=1, s=0 \ldots 1$, and $f_{B}(b)=1, b=0 \ldots 1$ are the probability distribution functions for $s$ and $b$ respectively. The probability density function of $z$ is shown in the figure below:

$$
f_{z}(z)=\left\{\begin{array}{ccc}
\frac{\pi}{2} \cdot z & \text { if } & 0 \leq z \leq 1 \\
i \cdot z \cdot\left[\ln \left(1+i \cdot \sqrt{z^{2}-1}\right)-\ln \left(i+\sqrt{z^{2}-1}\right)\right] & \text { if } & 1 \leq z \leq \sqrt{2}
\end{array}\right.
$$

Within the range $0 \leq z \leq 1$, expected utility (allowing it to be negative for some individuals) has a simple density as:

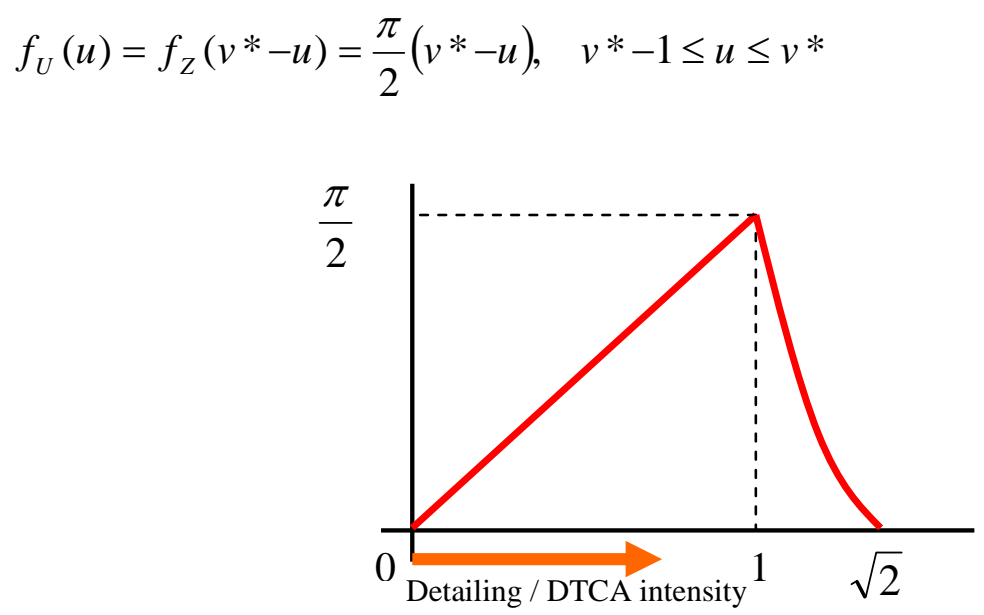

The probability density function of $z$ on the interval $(0, \sqrt{2})$.

\footnotetext{
${ }^{16}$ If there is positive correlation between benefits and risk (e.g. both are likely to increase with age) our analysis should be viewed as conservative in the sense that relying primarily on safety signals will lead to less precision in crafting regulatory rules and the subsequent exclusion of individuals who could have benefited greatly from taking the drug.
} 
We will rule out the case of $1 \leq z \leq \sqrt{2}$ since the expected utility is always less than zero (regardless of the value of $v^{*}$ for a particular drug) so physicians would never prescribe a drug to such patients.

To see this, note that the position of the unit square in the real plane is irrelevant for the distribution of $z$, so we simplify the analysis by relocating the square at $[-1,0] \mathrm{x}[-$ 1,0] so that $z=\sqrt{b^{2}+r^{2}}$. Then we have

$$
F_{Z}(z)=P[Z \leq z]=P\left[\sqrt{R^{2}+B^{2}} \leq z\right]
$$

Since $R$ and $B$ are independent,

$$
F_{Z}(z)=\int_{-\infty}^{\infty} P\left(\sqrt{R^{2}+B^{2}} \leq z \mid R=r\right) f_{R}(r) d r
$$

Letting $R=r$,

$$
F_{Z}(z)=\int_{-\infty}^{\infty} P\left(\sqrt{r^{2}+B^{2}} \leq z\right) f_{R}(r) d r
$$

Note that $P\left[\sqrt{r^{2}+B^{2}} \leq z\right]=P\left[B \leq \sqrt{z^{2}-r^{2}}\right]=F_{B}\left(\sqrt{z^{2}-r^{2}}\right)$, so

$$
F_{Z}(z)=\int_{-\infty}^{\infty}\left[F_{B}\left(\sqrt{z^{2}-r^{2}}\right)\right] f_{R}(r) d r
$$

Then

$$
f_{Z}(z)=\frac{d F_{Z}(z)}{d z}=\frac{d}{d z}\left[\int_{-\infty}^{\infty}\left[F_{B}\left(\sqrt{z^{2}-r^{2}}\right)\right] f_{R}(r) d r\right]=\int_{-\infty}^{\infty} \frac{d F_{B}\left(\sqrt{z^{2}-r^{2}}\right)}{d z} f_{R}(r) d r
$$

Now note that $\frac{d F_{B}(b)}{d z}=\frac{d F_{B}(b)}{d b} \cdot \frac{d b}{d z}=f_{B}(b) \cdot \frac{d b}{d z}$ where $\frac{d b}{d z}=\frac{z}{\sqrt{z^{2}-r^{2}}}$. So

$$
f_{Z}(z)=\int_{-\infty}^{\infty} \frac{z}{\sqrt{z^{2}-r^{2}}} \cdot f_{B}\left(\sqrt{z^{2}-r^{2}}\right) f_{R}(r) d r=\int_{-\infty}^{\infty} \frac{z}{\sqrt{z^{2}-r^{2}}} \cdot f_{B}(b) f_{R}(r) d r=\int \frac{z}{\sqrt{z^{2}-r^{2}}} \cdot(1 \times 1) d r
$$


Breaking the integral into two parts,

$$
f_{Z}(z)=\left\{\begin{array}{lll}
\int_{0}^{z} \frac{z}{\sqrt{z^{2}-r^{2}}} d r & \text { if } & 0 \leq z \leq 1 \\
\int_{\sqrt{z^{2}-1}}^{1} \frac{z}{\sqrt{z^{2}-r^{2}}} d r & \text { if } & 1 \leq z \leq \sqrt{2}
\end{array}\right.
$$

Therefore,

$$
f_{Z}(z)=\left\{\begin{array}{ccc}
\frac{\pi}{2} \cdot z & \text { if } & 0 \leq z \leq 1 \\
i \cdot z \cdot\left[\ln \left(1+i \cdot \sqrt{z^{2}-1}\right)-\ln \left(i+\sqrt{z^{2}-1}\right)\right] & \text { if } & 1 \leq z \leq \sqrt{2}
\end{array}\right.
$$




\section{Appendix B: Derivation of Modified Dorfman-Steiner Rule.}

$\underset{p, A}{\operatorname{Max}}(1-w(p, A)) \cdot[x(p, A) \cdot(p-c)]-A$

First order condition with respect to $A$

$$
\begin{aligned}
& (1-w) \cdot\left[\frac{\partial x}{\partial A} \cdot(p-c)\right]-\frac{\partial w}{\partial A} \cdot x \cdot(p-c)=1 \\
& (1-w) \cdot\left[\frac{\partial x}{\partial A} \cdot \frac{A}{x} \cdot \frac{x}{A} \cdot p \cdot \frac{p-c}{p}\right]-\frac{\partial w}{\partial A} \cdot \frac{A}{w} \cdot \frac{w}{A} \cdot x \cdot p \cdot \frac{p-c}{p}=1 \\
& \left(\frac{p-c}{p}\right) \cdot\left[(1-w) \cdot\left(\frac{\partial x}{\partial A} \cdot \frac{A}{x}\right)-w \cdot\left(\frac{\partial w}{\partial A} \cdot \frac{A}{w}\right)\right]=\frac{A}{p \cdot x} \\
& {[A] \quad\left(\frac{p-c}{p}\right) \cdot\left[(1-w) \cdot \varepsilon_{x, A}-w \cdot \varepsilon_{w, A}\right]=\frac{A}{p \cdot x}}
\end{aligned}
$$

First order condition with respect to $p$

$$
\begin{aligned}
& (1-w) \cdot\left[\frac{\partial x}{\partial p} \cdot(p-c)+x\right]-\frac{\partial w}{\partial p} \cdot x \cdot(p-c)=0 \\
& (1-w) \cdot\left[\frac{\partial x}{\partial p} \cdot \frac{p}{x} \cdot \frac{(p-c)}{p} \cdot x+x\right]-\frac{\partial w}{\partial p} \cdot \frac{p}{w} \cdot \frac{(p-c)}{p} \cdot x \cdot w=0 \\
& \left(\frac{p-c}{p}\right) \cdot\left[(1-w) \cdot\left(\frac{\partial x}{\partial p} \cdot \frac{p}{x}\right)-w \cdot\left(\frac{\partial w}{\partial p} \cdot \frac{p}{w}\right)\right]+(1-w)=0 \\
& {[p] \quad\left(\frac{p-c}{p}\right)=\frac{1-w}{w \cdot \varepsilon_{w, p}-(1-w) \cdot \varepsilon_{x, p}}}
\end{aligned}
$$

Dividing [A] by [p] results in the following modified Dorfman - Steiner Rule:

$$
\frac{A}{(1-w) \cdot p \cdot x}=\frac{(1-w) \cdot \varepsilon_{x, A}-w \cdot \varepsilon_{w, A}}{w \cdot \varepsilon_{w, p}-(1-w) \cdot \varepsilon_{x, p}}
$$

